\title{
Observational Analysis of Extratropical Cyclone Interactions with Northeast Pacific Sea Surface Temperature Anomalies
}

\author{
BRIANA PHILLIPS AND LARRY O’NEILL \\ College of Earth, Ocean and Atmospheric Sciences, Oregon State University, Corvallis, Oregon
}

(Manuscript received 17 November 2019, in final form 4 April 2020)

\begin{abstract}
This study examines the interaction between a northeast Pacific upper-ocean thermal anomaly and individual fall storm events between 2013 and 2016. In 2013, a large upper-ocean thermal anomaly formed in the Gulf of Alaska (GOA) with sea surface temperatures (SST) warmer than $4^{\circ} \mathrm{C}$ above the climatological norm. Formation of the anomaly was associated with a persistent atmospheric ridge in the GOA that produced a lull in storm activity in the boreal winter of 2013/14. While reduced storm activity was the apparent cause of this SST anomaly, we present cases where extratropical cyclones significantly eroded its mixed layer heat content on synoptic time scales. Case studies during the 4-yr period 2013-16 using satellite and Argo hydrographic observations show that early fall storms produced the largest surface heat fluxes and the greatest cooling of SST. The magnitude of thermal energy transfer from the ocean to the atmosphere during individual storm events was then determined using vertically integrated heat budgets based on Argo temperature profiles and reanalysis surface heat fluxes. Storm-induced surface heat flux anomalies accounted for approximately $50 \%$ of the warm anomaly cooling observed by Argo profiles. This rapid heat loss occurred over time scales of approximately 3-5 days. The decay of the warm SST anomaly (SSTa) occurred much more quickly than expected from classic thermal damping by SST-induced turbulent heat fluxes, which may be attributed here at least partly to much shallower mixed layers during early fall. Analysis of the individual surface flux terms indicated that the latent heat flux was the dominant contributor to storm-induced heat exchange across the air-sea interface.
\end{abstract}

\section{Introduction}

The simultaneous occurrence of sea surface temperature anomalies (SSTa) and atmospheric circulation anomalies in the northeast Pacific (NEP) are commonly analyzed on monthly or seasonal time scales based on the persistence of ocean subsurface temperature anomalies and the coupled effects on climate (Frankignoul 1985; Barnston and Livezey 1987; Deser et al. 1996; Mantua et al. 1997; Di Lorenzo et al. 2008; Johnstone and Mantua 2014; Di Lorenzo and Mantua 2016; Wills and Thompson 2018). Frankignoul and Hasselmann (1977) and Alexander and Penland (1996) showed that stochastic atmospheric variability can generate SST anomalies away from regions of strong currents. Once formed, these anomalies decay through a thermal damping mechanism mediated by anomalous SST-induced surface heat fluxes. Barsugli and Battisti (1998) further

\footnotetext{
Corresponding author: Larry W. O’Neill, loneill@coas.oregonstate. edu
}

suggested that the SST anomalies imprint onto the local boundary layer temperature, reducing the SST-induced surface heat fluxes and slowing the SSTa decay, in a process they call reduced thermal damping. They were able to remove established SSTa through white-noise atmospheric forcings over a seasonal to half-year time period. Frankignoul and Hasselmann (1977) found that the SSTa frequency spectra flatten out, or decay, on average over a period of 4.5 months. While the mean seasonal SSTa decay does give a general trend, it does not resolve the contribution from singular synoptic weather events, particularly storms. Recently, Scannell et al. (2016) suggested that synoptic weather variability may influence the size and frequency of marine heat waves over time. This study investigates interactions between a number of storms and warm SSTa within the NEP during the period 2014-16 when the NEP experienced an anomalously warm upper ocean. We show that storm-induced surface heat fluxes efficiently erode the warm upper-ocean heat anomalies much quicker than expected from previous work. 

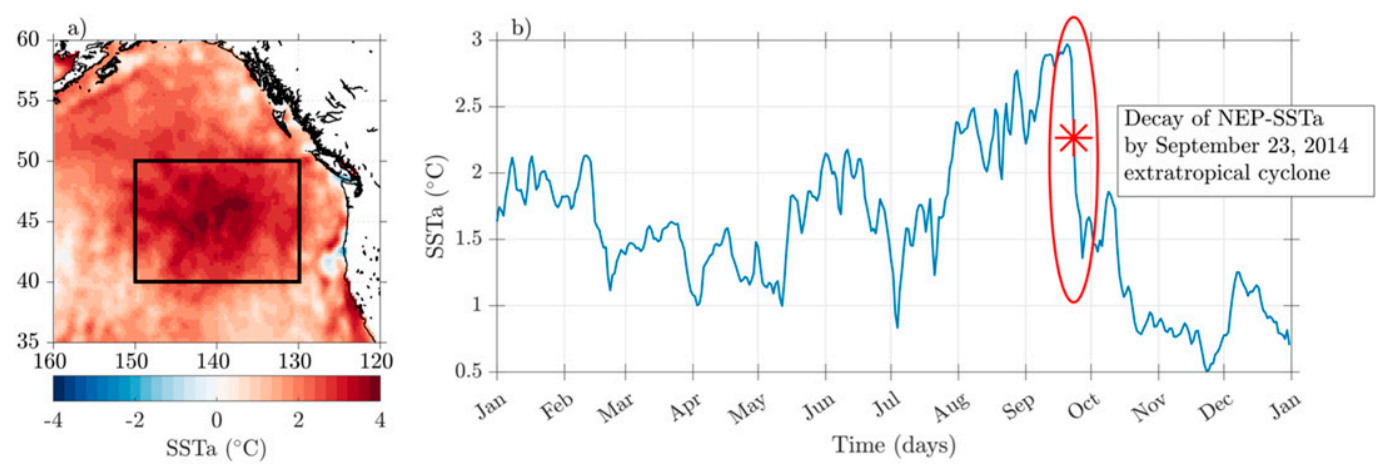

FIG. 1. (a) Map showing the SSTa from the Reynolds SST analysis on 21 Sep 2014. The black box indicates the spatial domain of interest $\left(45^{\circ}-50^{\circ} \mathrm{N}, 130^{\circ}-150^{\circ} \mathrm{W}\right)$. (b) Time series of the daily spatially averaged Reynolds reanalysis northeast Pacific SSTa (NEP-SSTa) within the box in (a) during 2014. The ellipse indicates a period of rapid decay of the NEP-SSTa over a 7-day period centered on 23 Sep 2014 during an extratropical cyclone event referred to here as E2. The asterisk in (b) denotes the time and SSTa of a large extratropical cyclone affecting the domain discussed in this analysis.

On 23 September 2014 a large extratropical cyclone passed over a warm anomaly in the Gulf of Alaska (GOA), hereafter known as the northeast Pacific sea surface temperature anomaly (NEP-SSTa), resulting in widespread cooling of the sea surface. This single storm eroded nearly the entire surface thermal anomaly and reformation of the strongest SSTa signal was not until the following spring in 2015. The evolution of the SSTa field during this storm is shown by the time series in Fig. 1b, where the ellipse highlights a dramatic cooling over a 5-day period centered on the storm's date (shown by the red asterisk). This figure also shows the areal average daily SSTa taken over the NEP-SSTa region $40^{\circ}-$ $50^{\circ} \mathrm{N}, 130^{\circ}-150^{\circ} \mathrm{W}$, as indicated by the black box in Fig. $1 \mathrm{a}$.

Intensive efforts within the scientific community have been aimed at explaining the formation, persistence, and variability of the warm NEP-SSTa. During the boreal winter of 2013/14 a warm anomaly amplified and resulted in record-breaking high SST and a persistent upper-ocean thermal anomaly. It has been termed The Blob or Warm Blob (Bond et al. 2015) and called a marine heatwave (Di Lorenzo and Mantua 2016); in this paper, it is referred to as the NEP-SSTa. The NEP-SSTa was distinct from the coastal marine heatwave that occurred during 2014-16 along the North American west coast (Gentemann et al. 2017). There are currently three primary mechanisms hypothesized to explain the formation and maintenance of the NEP-SSTa.

The first hypothesis was based on a persistent atmospheric blocking ridge that coincided in space and time with the formation of the NEP-SSTa during the winter of 2013/14 (Wang et al. 2014; Hartmann 2015; Bond et al. 2015; Amaya et al. 2016; Di Lorenzo and Mantua 2016; $\mathrm{Hu}$ et al. 2017). Anticyclonic surface wind anomalies around a positive 500-hPa geopotential height anomaly acted against the prevailing westerlies, thereby shifting the strong Pacific jet stream northward (Swain et al. 2014; Bond et al. 2015; Swain et al. 2017). The SST response to the atmospheric circulation anomaly was hypothesized to be driven primarily by changes in surface heat fluxes, reduced wind-driven upwelling, and anomalous horizontal advection of colder water into the GOA from the Bering Sea and Alaskan Shelf water (Bond et al. 2015; Myers et al. 2018).

The second hypothesis was that the NEP-SSTa was an extratropical expression of normal modes of tropical oceanic variability. Hartmann (2015) concluded that the 500-hPa geopotential anomaly was a product of the North Pacific mode (NPM) originally forced by the SSTa in the tropical west Pacific, which then forced the atmosphere, with subsequent impacts on the NEP-SSTa in the extratropics. Di Lorenzo and Mantua (2016) related the originating structure of the NEP-SSTa in 2013/14 to the North Pacific Gyre Oscillation (NPGO) and the resulting variability of the NEP-SSTa from 2014/15 as a transition into the positive phase of the Pacific decadal oscillation (PDO). The GOA sea level pressure anomaly in 2013/14 has also been attributed to having characteristics of the tropical Northern Hemisphere (TNH) pattern (Liang et al. 2017). Liang et al. (2017) found prolonged periods of Pacific warm events in the past, but the 2013-15 period was exceptional since it had the greatest amplitude of warming within the contemporary time period.

The third hypothesis is based on extreme warm SST in the northeast Pacific being a manifestation of global warming. The loss of sea ice in the Arctic and the adjacent marginal seas when coupled with a positive SSTa in the tropics induces anomalous atmospheric circulation in the extratropics (Lee et al. 2015). Rising mean surface temperatures would produce a positive thermodynamic 
feedback that intensifies the North Pacific Oscillation (NPO) variance and more extreme warm SSTa in the tropics (Di Lorenzo and Mantua 2016). This would then feed back to the extratropics through atmospheric teleconnections into a persistent ridge-like pattern (Di Lorenzo and Mantua 2016).

Ultimately, the general scientific consensus is that NEP-SSTa formed by atmospheric forcing. Its variability is forced by tropical teleconnections through ENSO and shifting of the PDO phase, while its persistence is due to anomalous atmospheric circulation anomalies, which reduced heat loss from the ocean to the atmosphere. The specific mechanisms or modes that cause the atmospheric forcing anomalies are still being debated. This research is not driven by answering the question about isolating which long-term climate oscillation is responsible for the NEP-SSTa formation. Rather, we seek to understand the impact that synoptic storm events have on the NEP-SSTa that have heretofore not been considered. It is shown in this analysis that the NEP-SSTa eroded over just a few days, much faster than would be predicted based on thermal damping of typical midlatitude SST anomalies from the theory of Frankignoul and Hasselmann (1977). Storms during the period of 2013-16 affected the NEPSSTa in different ways and significantly shaped the evolution of the NEP-SSTa. Nearly all previous research has investigated interactions between the NEP-SSTa and the atmosphere on seasonal and longer time scales. Here, we document significant interactions between individual synoptic weather events and the NEP warm anomalies.

This research seeks to understand how the interaction with high-frequency, synoptic-scale atmospheric forcing affects the upper-ocean thermal anomaly. Heat is the fundamental variable of interest in addressing these questions: What is the dominant path of thermal energy during these interactions? To what extent do extratropical cyclones play a role in dissipating such a large volume of heat? The analysis consists of determining the best time to observe these interactions and then performing vertically integrated heat budgets that focus on heat fluxes across the air-sea interface. Categorization of the response of the upper-ocean thermal anomaly to storms is described in section 2. The analysis of the surface heat fluxes and the vertically integrated heat budgets is described in section 3. Results are presented in section 4. A discussion of the interpretation of the results as well as conclusions are given in section 5 .

\section{Categorization of storm-induced upper-ocean thermal responses}

Case studies of the response of the upper-ocean thermal structure to extratropical cyclones were performed using satellite SST and wind observations and Argo subsurface temperature observations. The goal was to identify events where large storm-induced flux anomalies occurred in conjunction with rapid NEP-SSTa cooling. The categorization of these case studies was based on visual inspection of satellite and subsurface observations. Interactions between synoptic weather events and the NEP-SSTa are examined during the period $2014-15$ within the approximate spatial domain of $40^{\circ}-50^{\circ} \mathrm{N}, 130^{\circ}-150^{\circ} \mathrm{W}$. During this $2-\mathrm{yr}$ period, the NEP-SSTa was fully formed and responses were more explicit than in 2013 when the NEP-SSTa was forming and in 2016 when it was decaying. Throughout this period, the NEP-SSTa was not stationary but the analysis domain remained fixed. This assumed that the thermal anomaly resided within the boundaries and that the full 100-m-deep subsurface anomaly was present beneath the SSTa at all times.

\section{a. Observations used}

Measurements of SST were taken from the National Oceanic and Atmospheric Administration (NOAA) Advanced Very High Resolution Radiometer (AVHRRonly), daily Optimum Interpolation Sea Surface Temperature version 2 dataset (OISSTv2) (Reynolds et al. 2007), referred to as Reynolds SST analysis hereafter. The $0.25^{\circ}$ spatial grid at daily intervals provides adequate resolution to study synopticscale variability of the SSTa. A key advantage of using this dataset compared with others is its long data record and relatively homogeneous error statistics. A daily-mean climatology was calculated by averaging over a $30-y r$ based period (1981-2010) of daily SST as a function of calendar day. This daily climatology was removed from the daily Reynolds SST analysis to create the daily anomaly.

Surface wind observations were taken from the Advanced Scatterometer on board $\mathrm{MetOp}$ - $\mathrm{A}$ (ASCAT-A) and $\mathrm{Met} O \mathrm{P}$ $B$ (ASCAT-B) (EUMETSAT/OSI SAF 2010, 2013). The ASCAT instruments are active, dual fan-beam scatterometers that measure microwave backscatter from the wind-roughened sea surface and have two $500-\mathrm{km}$-wide observational swaths separated by a $475-\mathrm{km}$ nadir gap where no surface wind observations are collected. ASCAT has a nominal $50-\mathrm{km}$ spatial resolution, samples the midlatitudes up to twice per day and is capable of measuring storm force winds in extratropical cyclones. Since the ASCAT C-band radar is relatively insensitive to rain, it is able to estimate the surface wind speed and direction in allweather conditions. Its ability to provide accurate wind measurements in rain is another significant advantage in this analysis since extratropical cyclones are frequently accompanied by localized regions of moderate to heavy rainfall.

Argo floats were used in this analysis to determine the response of the subsurface temperature down to $100 \mathrm{~m}$ (Argo 2020). The Argo model used for most floats in this 
TABLE 1. Criteria for categorization of ocean response to storms during 2014/15 when the NEP-SSTa surface signature was at its peak. High wind speeds were determined to be any event with cyclonic motion and surface wind speeds greater than $15 \mathrm{~m} \mathrm{~s}^{-1}$. Significant cooling was characterized as a $\Delta \mathrm{SST}$ a of $1.5^{\circ} \mathrm{C}$ over a large area $\left(\sim 10^{\circ}\right.$ lon $\times 10^{\circ}$ lat $)$ within the analysis domain $\left(45^{\circ}-50^{\circ} \mathrm{N}, 130^{\circ}-150^{\circ} \mathrm{W}\right)$.

\begin{tabular}{lcccc}
\hline \hline Category & $\Delta$ SSTa $\left({ }^{\circ} \mathrm{C}\right)$ & Surface wind speeds $\left(\mathrm{m} \mathrm{s}^{-1}\right)$ & No. of events & Characterization \\
\hline I & $\geq 1.5$ & $\geq 15$ & 23 & Large $\Delta$ SSTa, high winds \\
II & $<1.5$ & $\geq 15$ & 32 & Low $\Delta$ SSTa, high winds \\
III & $\geq 1.5$ & $<15$ & 18 & Large $\Delta$ SSTa, low winds \\
\hline
\end{tabular}

region was the Autonomous Profiling Explorer-260 (APEX). Higher-resolution vertical sampling is made near the surface, with measurements taken every $5 \mathrm{~m}$ between the surface and $100 \mathrm{~m}$. The time between surface data transmissions is approximately 11 days, with 10 of those days spent freely advecting with the current at $1-2 \mathrm{~km}$. The spatial difference between transmissions was roughly $30-40 \mathrm{~km}$. Despite using the common APEX-260, there is still a reduction in Argo float density in the open Pacific relative to waters near the coast. Therefore, in situ measurements in the NEP-SSTa region are sparse.

\section{b. Categorization of wind speed and SSTa}

Daily maps during the 2-yr period 2014-15 of surface wind speed from ASCAT-A and B and DSSTa (the change in SSTa before and after the passing of a storm) from the Reynolds reanalysis were created, analyzed, and categorized. This subset time period was used when the surface signature of the NEP-SSTa was at its greatest. Categorization of high wind speed observations was determined visually to be any event with cyclonic circulation of wind vectors and speeds greater than $15 \mathrm{~m} \mathrm{~s}^{-1}$. Large $\Delta$ SSTa values were determined to be any large area $\left(\sim 10^{\circ}\right.$ lon $\times 10^{\circ}$ lat $)$ within the analysis domain with a minimum negative tendency of $1.5^{\circ} \mathrm{C}$ over a 5-day period, with 2 days before and 2 days after the date of interest. This 5-day differential was chosen based on observations of how long it usually took for an extratropical cyclone to fully pass through the NEPSSTa region. The approximate origin and path of each storm was determined using ERA-Interim 850-hPa relative vorticity (not shown). Relative vorticity has been shown to be a better field for identifying synoptic features during the early stages of a cyclones life as the large-scale background variability is reduced relative to other tracking variables such as MSLP (Hoskins and Hodges 2002). Reverse tracking of $850-\mathrm{hPa}$ relative vorticity from the date of interest helped to confirm that no storm had originated over the NEP-SSTa but rather originated from farther upstream. The storms and subsequent ocean responses were separated into three categories based on the areal-average ASCAT wind speed, the magnitude of the Reynolds $\triangle$ SSTa, and inspection of the 850-hPa relative vorticity from ERAInterim 6-h data (Dee et al. 2011). The criteria and the number of events observed in each of the three categories are presented in Table 1.

Category I events predominantly occurred in the fall where Argo temperature observations showed shallow mixed layers and the arrival of fall storms lead to significant cooling. Argo profiles during category II events, which occurred primarily in winter, showed deep mixed layers not being affected enough by large storms to cause substantial cooling. Category III events appearing in summer had highly stratified water columns and shallow mixed layers. Significant cooling in the category III events could be attributed to changes in cloud cover and moderate wind speeds. From this analysis, category I events that occurred during early fall were analyzed further based on the large sensitivity of the warm anomaly to early season storms. This was determined to be the most optimal period in studying the heat redistribution from air-sea interactions based on the simultaneous occurrence of both high wind conditions and large changes in the SSTa.

\section{c. Early fall extratropical cyclones}

The first fall storms that occurred from 2013-16 are analyzed further in section 4 and can be seen in the observational ASCAT-A and B surface wind speed fields in Fig. 2. Event 1 (E1) occurred on 19 September 2013; event 2 (E2) occurred on 23 September 2014, event 3 (E3) on 1 October 2015, and event 4 (E4) on 11 October 2016. These maps show that these four storms in question occupied a large area and were well developed. During these four events, Argo observations were located within the NEP-SSTa (shaded area, Fig. 3, left column). Vertically integrated temperature differences $(\Delta T)$ from the surface down to 50 and $100 \mathrm{~m}$ from the Argo profiles were calculated from before the storm arrived to after the storm had fully passed. Sparse Argo observations in the open Pacific coupled with low temporal sampling restricted the ability to have continuous measurements for when the storm passed over the NEP-SSTa. Therefore, the Argo observational period contained the storm and the surfacing of the profiler never coincided with the exact 

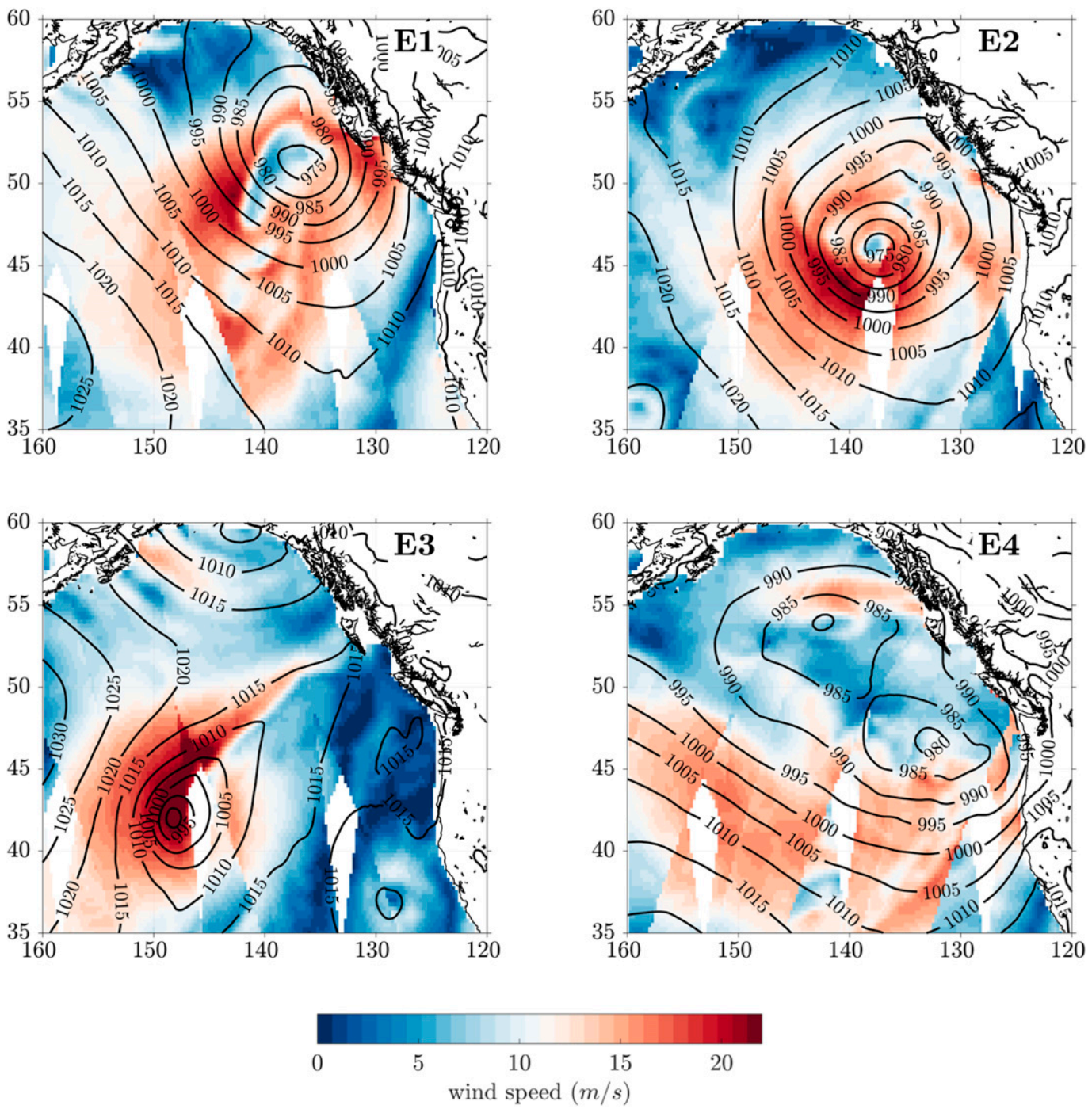

FIG. 2. Maps of the daily-averaged ASCAT-A and ASCAT-B surface wind speed fields (shading) and the minimum ERA5 sea level pressure (SLP; hPa; contours) during the day of the events that are referenced as E1 (19 Sep 2013), E2 (23 Sep 2014), E3 (1 Oct 2015), and E4 (13 Oct 2016).

storm arrival and departure date. The magnitude of the $\triangle$ SSTa from E1-E4 can be seen as the shaded area in Fig. 3 (right column). Values of $\Delta T$ from the surface to $50 \mathrm{~m}$ are indicated by the markers in Fig. 3 (right) as circles for cooling and squares for warming. Zonaldepth sections of upper-ocean potential temperature anomaly from $2012-16$ are shown in Figs. $4 \mathrm{a}-\mathrm{c}$ at $45^{\circ} \mathrm{N}$ along $150^{\circ}, 140^{\circ}$, and $130^{\circ} \mathrm{W}$, respectively, which bisect the NEP-SSTa. The monthly potential temperature anomaly was calculated from the NCEP GODAS ocean state potential temperature relative to the 19812010 monthly climatology (NCEP 2006). The approximate timing of E1-E4 can be seen in Fig. 4 as the dashed vertical lines. A brief description of observed winds, the surface and subsurface temperature anomalies, as well as select Argo floats during E1-E4 is given below.

\section{1) EARLY FALL STORMS}

ASCAT-B (ASCAT-A) observations showed a maximum wind speed of $23 \mathrm{~m} \mathrm{~s}^{-1}\left(21 \mathrm{~m} \mathrm{~s}^{-1}\right)$ within the 2013 storm that had a minimum sea level pressure (SLP) of $971 \mathrm{hPa}$ according to ERA5 (Fig. 2, E1) (C3S 2017). In 2014 the storm had a minimum SLP of $972 \mathrm{hPa}$ and observed surface wind speeds in both ASCAT-A and ASCAT-B of $24 \mathrm{~m} \mathrm{~s}^{-1}$ (Fig. 2, E2). In 2015 ERA5 shows a minimum SLP of $988 \mathrm{hPa}$ and both ASCAT-A and ASCAT-B measured surface wind speeds up to $24 \mathrm{~m} \mathrm{~s}^{-1}$ (Fig. 2, E3). In contrast to the other three 

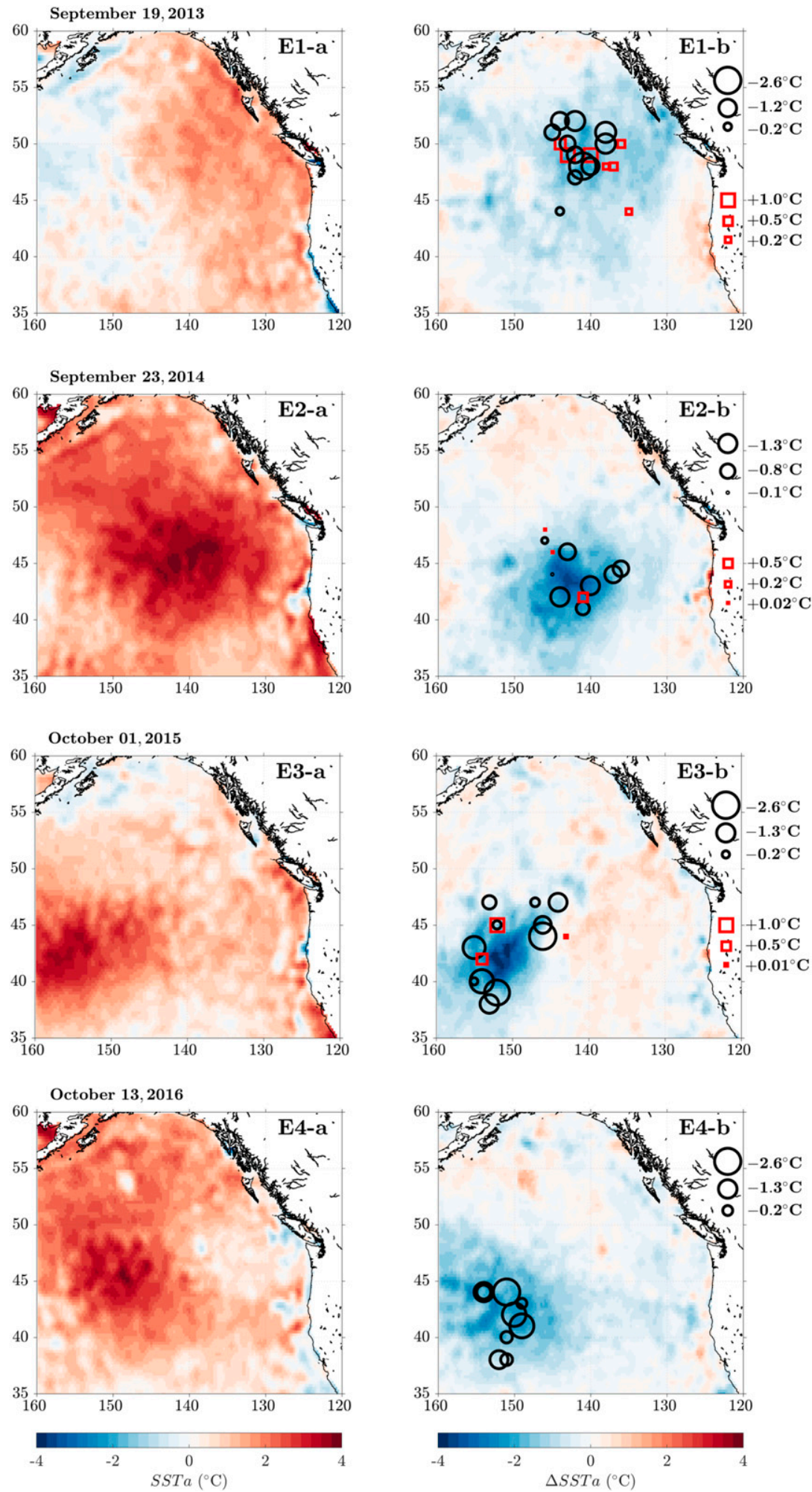

FIG. 3. (left) Maps of the the SSTa from the Reynolds SST analysis 2 days prior to events E1-E4 highlighted in Fig. 2. (right) Maps of the Reynolds $\Delta$ SSTa (shading) over a 5-day period centered on each storms date with the observed Argo vertically integrated $\Delta T$ (markers) from the surface to $50 \mathrm{~m}$. Black circles indicate cooling and red squares indicate warming with values given for the maximum, mean, and minimum $\Delta T$ for each event. The markers are scaled according to the reference markers on the right side of each panel. 

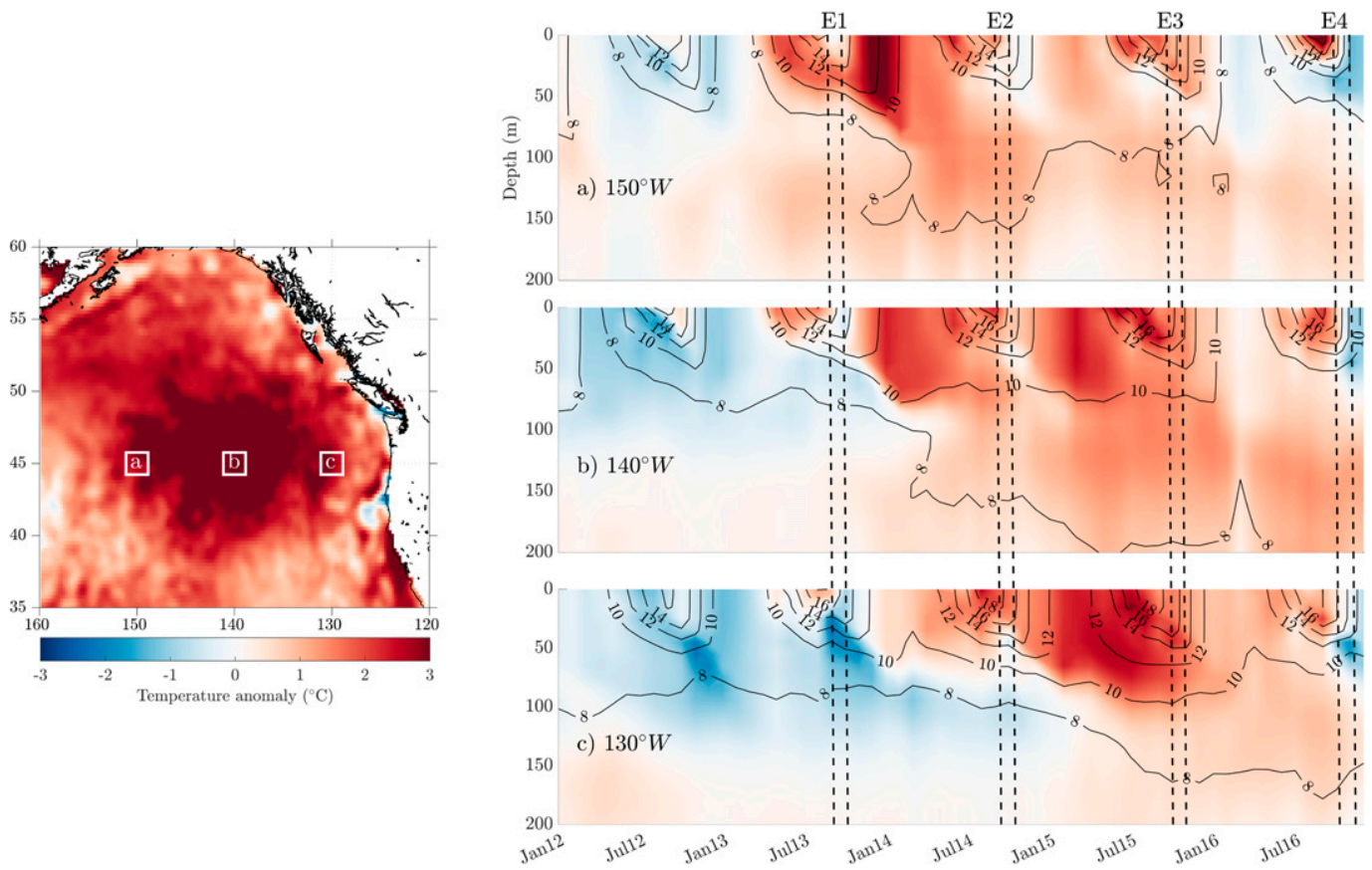

FIG. 4. (left) Map of the SSTa from the Reynolds SST analysis (shading) on 21 Sep 2014 showing the locations of the time-depth sections. The three locations are along $45^{\circ} \mathrm{N}$ and (a) $150^{\circ}$, (b) $140^{\circ}$, and (c) $130^{\circ} \mathrm{W}$. (right) Timedepth sections of the monthly averaged potential temperature anomaly (shading) from the NCEP GODAS oceanstate estimate relative to 1981-2010 monthly climatology for the period 2012-16 overlaid by the potential temperature (contours) at the three locations in (a)-(c). Color bar is valid for all shading and the time range of each event (E1-E4) is given by the vertical line.

storms, the surface winds during the 2016 storm did not form a closed circulation. Instead, this was more of a persistent high wind event over the strongest SSTa. Surface observations over the entire area show moderate to high wind speeds reaching up to $20 \mathrm{~m} \mathrm{~s}^{-1}\left(18 \mathrm{~m} \mathrm{~s}^{-1}\right)$ in ASCAT-B (ASCAT-A) and a minimum SLP in ERA5 of 977 hPa (Fig. 2, E4).

\section{2) EARLY FALL SURFACE AND SUBSURFACE TEMPERATURE ANOMALIES}

In fall 2013, the NEP-SSTa was greater than $2^{\circ} \mathrm{C}$ between $140^{\circ}$ and $160^{\circ} \mathrm{W}$ (Fig. 3, E1-a). The subsurface anomaly had reached $40-60-\mathrm{m}$ depth between $140^{\circ}$ and $150^{\circ} \mathrm{W}$ by September 2013 (Figs. 4a,b). This resulted in a cooling over the entire anomaly with a maximum $\triangle \mathrm{SSTa}$ of $-2.3^{\circ} \mathrm{C}$ over a 5-day period (Fig. 3, E1-b). There were 19 Argo subsurface temperature profiles in the area during this event. Vertically integrated temperature differences over both depths resulted in 12 observations experiencing cooling (circles in Fig. 3, E1-b).

In September 2014, the NEP-SSTa had a strong warm surface anomaly spanning the entire domain (Fig. 3, E2-a) and a subsurface thermal anomaly of $1^{\circ} \mathrm{C}$ that reached $140 \mathrm{~m}$ (Figs. 4a,b) between $140^{\circ}$ and $150^{\circ} \mathrm{W}$. The 23 September 2014 storm was strong enough to completely erode the $4.2^{\circ} \mathrm{C}$ (Fig. 3, E2-a) SSTa near the center and reduce the subsurface temperature anomaly down to $\sim 50 \mathrm{~m}$. The storm resulted in a $\Delta S S T a$ of $-3.6^{\circ} \mathrm{C}$ over a 5-day period (Fig. 3, E2-b). There were 11 Argo subsurface temperature profiles within the area with 8 (7) of the profiles from the surface to $50 \mathrm{~m}(100 \mathrm{~m})$ experiencing a decrease in vertically integrated temperature (circles in Fig. 3, E2-b).

By October 2015, the NEP-SSTa surface signal had migrated to the west (Fig. 3, E3-a). The storm was on the outer edge of the spatial domain, which calls into question how much of the subsurface anomaly that originated around $140^{\circ} \mathrm{W}$ in $2013 / 14$ was affected. There was still a positive subsurface anomaly of $1^{\circ}-1.5^{\circ}$ at $60 \mathrm{~m}$ around $150^{\circ} \mathrm{W}$ (Fig. $4 \mathrm{a}$ ). The storm moved over a $4.3^{\circ} \mathrm{C}$ anomaly (Fig. 3, E3-a) and produced $4^{\circ} \mathrm{C}$ of cooling over a 5-day period (Fig. 3, E3-b). There were 14 Argo temperature profiles during this storm with 11 (12) of those profiles experiencing cooling from the surface to $50 \mathrm{~m}(100 \mathrm{~m})$; see circles in Fig. 3 (E3-b).

The surface and subsurface temperature anomaly during the 2016 events was most likely not the NEPSSTa that originated in the GOA. There was a break in the subsurface anomaly at $150^{\circ} \mathrm{W}$ between February and June 2016 (Fig. 4a). The SSTa, which was still $4^{\circ} \mathrm{C}$ centered around $45^{\circ} \mathrm{N}, 150^{\circ} \mathrm{W}$ (Fig. 3, E4-a), had a 

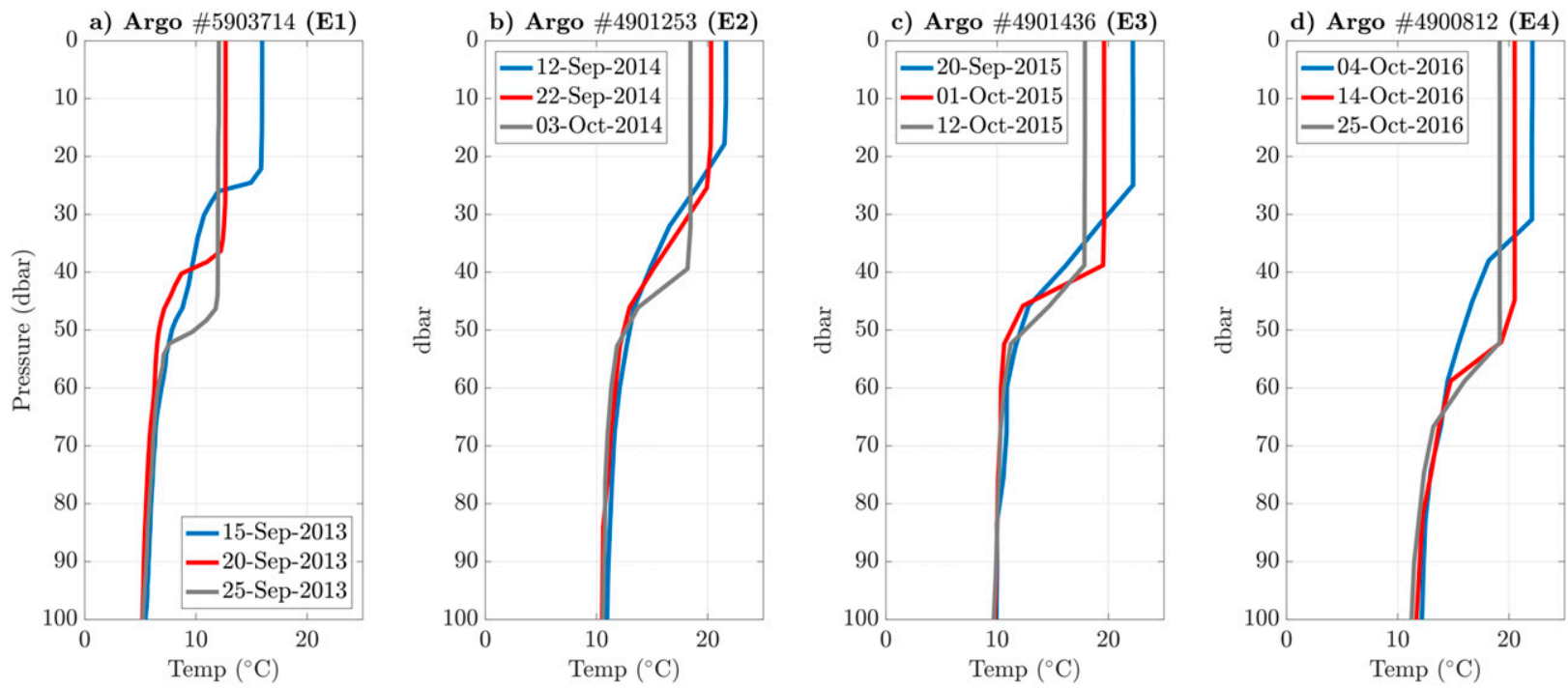

FIG. 5. Representative Argo profiles of subsurface temperature before (blue), during (red), and after (gray) the extratropical cyclone events highlighted in Fig. 2.

maximum cooling of $-2.7^{\circ} \mathrm{C}$ over a 5-day period (Fig. 3, E4-b). The nearly complete erosion of the subsurface thermal anomaly between 50 and $100 \mathrm{~m}$ can be seen in Figs. $4 \mathrm{a}-\mathrm{c}$ after E4 passed. There were nine Argo profiles in the area during this time with 9 (8) of those profiles experiencing cooling down to $50 \mathrm{~m}(100 \mathrm{~m})$; see circles in Fig. 3 (E4-b).

\section{3) Highlighted Argo observations}

Argo float 5903714 at $49^{\circ} \mathrm{N}, 142^{\circ} \mathrm{W}$ was situated near the maximum cooling on 19 September 2013. The mixed layer deepened $25 \mathrm{~m}$ over an 11-day period between consecutive Argo profiles (Fig. 5a), while the temperature below $\sim 60 \mathrm{~m}$ changed very little. Thus, vertical heat exchange below this depth was likely negligible during this storm. The profile of Argo float 4901253 showed a deepening mixed layer of $23 \mathrm{~m}$ and minor change in temperature past $\sim 60 \mathrm{~m}$ (Fig. $5 \mathrm{~b}$ ) during the 23 September 2014 storm. Argo float 4901436 was in the southwest quadrant of the 1 October 2015 storm and its temperature profile depicted a deepening of the mixed layer of $13 \mathrm{~m}$, while there was little temperature change below $\sim 75 \mathrm{~m}$ (Fig. 5c). Argo float 4900812 (Fig. 5d) saw a mixed layer deepening of $21 \mathrm{~m}$ and very little change in temperature below $\sim 75 \mathrm{~m}$.

The SSTa responses to E1-E4 are shown in the timelongitude plot in Fig. 6 as the Reynolds SSTa from 2013 to 2016 at $45^{\circ} \mathrm{N}, 125^{\circ}-160^{\circ} \mathrm{W}$. The horizontal boxes in Fig. 6 indicate when these fall storm events moved through the area. These four events not only had effects that were local during the Argo time period, but they also had long-lasting effects on the surface and possibly the subsurface of the thermal anomaly. In these cases, the warmest SSTa was eroded from the time when the storm passed until it reformed the following spring.

\section{Upper-ocean heat budget analysis}

The four events, E1-E4, shown in Fig. 2 are analyzed further to estimate how much thermal energy associated with the warm SSTa was transferred from the ocean to the atmosphere through surface heat fluxes enhanced by the storms. Temperature changes from ocean subsurface heat budgets at the discrete points shown by the markers in Fig. 3 were constructed from reanalysis surface heat fluxes and then compared to the vertically integrated change in temperature observed by those Argo profiles. Only those profiles that experienced cooling (black circles in Fig. 3, right) were further analyzed in this part of the analysis. This was based on the fact that surface heat fluxes during the storms were always negative, and therefore any temperature change due to storm-induced surface heat flux anomalies considered in isolation would cause cooling of the subsurface rather than warming. This portion of the analysis shows that select Argo profiles during these fall storms experienced rapid upper-ocean cooling due mainly to storm-induced extreme latent heat flux anomalies.

\section{a. Upper-ocean heat budget}

The change in temperature over time, from slow seasonal variations to stochastic forcing, can be described using the temperature tendency equation (Frankignoul 1985) vertically integrated over a depth $h$ : 


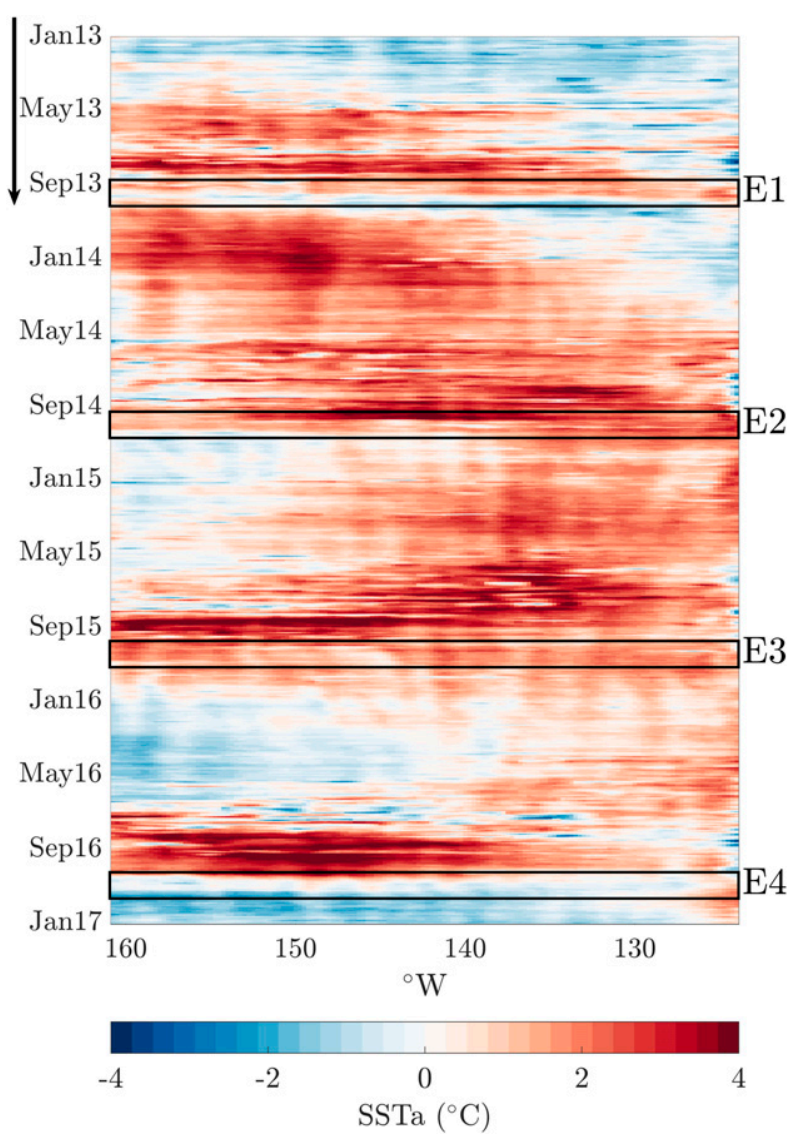

FIG. 6. Time-longitude plot of the Reynolds SSTa along $45^{\circ} \mathrm{N}$ between $125^{\circ}$ and $160^{\circ} \mathrm{W}$ showing the temporal evolution of the northeast Pacific SSTa (NEP-SSTa). The four events (E1-E4) highlighted in Fig. 2 are enclosed in the boxes.

$$
\begin{aligned}
\frac{\partial T_{m}}{\partial t}= & \underbrace{\frac{Q_{\text {net }}}{\rho_{0} C_{p} h}}_{\text {Term } A}+\underbrace{\left(\frac{w+w_{e}}{h}\right)\left(T_{b}-T_{m}\right)}_{\text {Term } B}-\underbrace{\mathbf{v} \cdot \nabla T_{m}}_{\text {Term } C} \\
& -\underbrace{\frac{Q_{\text {sw }}}{\rho_{0} C_{p} h}}_{\text {Term } D}+\underbrace{A \nabla^{2} T_{m}}_{\text {Term } E}
\end{aligned}
$$

where the changes in vertically averaged mixed layer temperature $T_{m}$ with time are dependent on the following:

1) Surface heating and cooling: a function of net surface heat flux $Q_{\text {net }}$, seawater density $\rho_{0}$, ocean specific heat $C_{p}$, and mixed layer depth $h$. The net flux $Q_{\text {net }}$ is composed of four components, latent heat $Q_{\mathrm{LH}}$, sensible heat $Q_{\mathrm{SH}}$, net thermal/longwave radiation $Q_{\mathrm{LW}}$, and net solar/shortwave radiation $Q_{\mathrm{Sw}}$ such that $Q_{\mathrm{net}}=Q_{\mathrm{LH}}+Q_{\mathrm{SH}}+Q_{\mathrm{LW}}+Q_{\mathrm{SW}}$.

2) Vertical mass flux or entrainment, parameterized as a function of the mean vertical motion $w$ at the base of the mixed layer, the vertical entrainment velocity across the base of the mixed layer $w_{e}, h$, and turbulent flux through the mixed layer base $T_{b}$ and $T_{m}$

3) Horizontal advection: composed of horizontal velocity $\mathbf{v}$ and spatial $T_{m}$ gradients.

4) Downward shortwave radiation penetrating the base of the mixed layer: a function similar to surface heating/cooling but now only concerned with $Q_{\mathrm{Sw}}$ at the base of $h$. This term is mainly important for shallow mixed layers during summer.

5) Horizontal diffusion from ocean eddies: dependent on the horizontal diffusion coefficient (Term $A$ ) and the divergence of the gradient of $T_{m}$ through ocean eddy interactions.

The following simplified version of Eq. (1) is used to focus on the change of vertically integrated temperature attributed only to changes in the net surface heat fluxes:

$$
\frac{\partial T_{m}}{\partial t}=\frac{Q_{\mathrm{net}}}{\rho_{0} C_{p} h}+R
$$

The term $R$ in Eq. (2) represents residual terms including the horizontal heat advection and entrainment/ detrainment of heat from below the thermocline that are not considered here due to lack of data. The term $Q_{\text {net }}$ is defined as negative when heat is leaving the ocean. Two fixed-depth values $h$ were investigated-50 and $100 \mathrm{~m}$ - to assess possible influences of entrainment and vertical advection in the mixed layer heat budget.

\section{b. Surface turbulent heat flux datasets}

A mean of four surface heat flux reanalysis datasets is used to estimate $Q_{\text {net }}$ in Eq. (2). The individual reanalysis datasets used include ERA-Interim, ERA5, NCEP-1, and NCEP-2. ERA-Interim from the European Centre for Medium-Range Weather Forecasts (ECMWF) covers the time period between 1979 and the present and has a nominal horizontal grid spacing of $78 \mathrm{~km}$ and produces 6-hourly analysis and 3-hourly forecast fields on the surface (Dee et al. 2011). ERA5 is the improved reanalysis product from the ECMWF, which has higher spatial $(31 \mathrm{~km})$ and temporal (hourly) resolution (C3S 2017). The National Centers for Environmental Prediction (NCEP) global reanalysis products, NCEP-1 and NCEP-2 [respectively Kalnay et al. (1996) and Kanamitsu et al. (2002)], are produced every $6 \mathrm{~h}$ and also have a horizontal grid spacing of $78 \mathrm{~km}$.

Since the upper ocean heat budgets depend critically on the accuracy of the gridded surface heat fluxes, these reanalysis surface heat flux datasets were compared with bulk fluxes estimated from surface meteorological 
observations from the Pacific Marine Environmental Laboratory (PMEL) OceanSITES network reference station, Ocean Station Papa, referred to as Station Papa hereafter (Cronin et al. 2015). Station Papa is located at $50.1^{\circ} \mathrm{N}, 144.9^{\circ} \mathrm{W}$ and is the closest moored buoy to the NEP-SSTa region with standard surface meteorological observations. For this comparison, collocation of the flux values within the grid cell containing the buoy was used. Surface observations from Station Papa are not incorporated into the reanalysis datasets used here. It therefore provides an independent evaluation of these gridded surface turbulent heat flux products within the North Pacific.

Daily estimates of latent heat flux $Q_{\mathrm{LH}}$ and sensible heat flux $Q_{\mathrm{SH}}$ were computed from the standard buoy meteorological observations using the COARE 3.0a bulk flux algorithm described by Fairall et al. (1996) (updated in 2003). The COARE 3.0a flux algorithm is based on the standard bulk formulation of the surface turbulent heat fluxes as

$$
\begin{aligned}
& Q_{\mathrm{SH}}=\rho_{a} C_{p} C_{e} U_{10}\left(T_{s}-\theta\right), \\
& Q_{\mathrm{LH}}=\rho_{a} L_{e} C_{h} U_{10}\left(q_{s}-q_{a}\right)
\end{aligned}
$$

where $\rho_{a}$ is the surface air density, $C_{p}$ is the specific heat capacity of air at a constant pressure, $L_{e}$ is the latent heat of evaporation, $C_{e}$ and $C_{h}$ are the $10-\mathrm{m}$ turbulent transfer coefficients, $U_{10}$ is the $10-\mathrm{m}$ wind speed, $T_{s}$ is the $\mathrm{SST}, \theta$ is the $2-\mathrm{m}$ air potential temperature, $q_{s}$ is the surface saturation specific humidity, and $q_{a}$ is the nearsurface atmospheric specific humidity.

Using Station Papa flux estimates calculated from Eq. (3) and the four reanalysis flux products, a comparison is performed from 2007 to 2018 using Taylor diagrams. Taylor diagrams provide a visual representation of the degree of correspondence between a reference and a set of "predictors," or test fields, in terms of three comparison statistics: the cross-correlation coefficient, the root-mean-square difference (RMSD), and the standard deviation of differences (Taylor 2001). In this analysis, the reference fluxes are from Station Papa and the four reanalysis flux products are the predictors. Two sets of comparisons using the Taylor diagrams were performed. The first comparison used all data in the time period and the second was only for extreme flux events. The second comparison assesses the capability of the predictors (reanalysis flux datasets) to estimate the storm-induced extreme surface turbulent heat fluxes, which is most relevant to this analysis. An extreme state is defined as a turbulent surface heat flux more than two standard deviations below the long-term mean $(\leq-2 \sigma)$. Since Station Papa only has observations available from 2007, the $2 \sigma$ threshold is calculated using their entire time record rather than the $30-y r$ mean that is used throughout the rest of this analysis. Figure 7 shows the time series of the surface latent heat flux (Fig. 7a) and sensible heat flux (Fig. 7b) from July 2007 to December 2018. Extreme state days are defined as any days below the red horizontal lines in Fig. 7. Gaps in the data were periods where at least one of the primary state variables used for computing the fluxes in Eq. (3) was missing, which includes wind speed, air temperature, relative humidity, and SST.

During the 11+-yr record, the buoy experienced 188 days that surpassed an extreme state surface latent heat flux of $-100 \mathrm{~W} \mathrm{~m}^{-2}$ and 172 days that surpassed an extreme state surface sensible heat flux threshold of $-43 \mathrm{~W} \mathrm{~m}^{-2}$. These extreme days and all other times were compared using the Taylor diagrams in Fig. 8. Figures $8 \mathrm{a}$ and $8 \mathrm{c}$ show the Taylor diagrams for surface latent heat flux and net surface heat flux, respectively, during all days, while Figs. $8 \mathrm{~b}$ and $8 \mathrm{~d}$ show the Taylor diagrams during extreme state days. Biases of each predictor relative to the reference are shown in Table 2 since the Taylor diagrams do not explicitly represent biases. All products were collocated as closely as possible in space and time, but are not exact. Differences in time steps as well as differing resolutions in the predictors to the point-source reference may be sources of error. Physical representations of forecast variables from ERA-Interim and ERA5 are also possible sources of error as flux variables are accumulated over 6-h (ERA-Interim) and hourly (ERA5) periods rather than being instantaneous as in the NCEP products. In the all-weather conditions, ERA5 overestimates the flux variances compared with the buoy data but is more highly correlated and has a lower RMSD than any other product considered here (Figs. 8a,c). ERA5 also compares to the buoy reference better in extreme conditions than the other products with respect to the Taylor statistics (Figs. 8b,d). All reanalysis products considered here produced a negative bias in the latent heat flux to some extent. The negative biases indicate that the reanalysis products overestimate ocean heat loss to the atmosphere compared to the buoy. The largest differences between the predictors and the reference occurred between October and January. This calls into question the reliability of either the predictor or the reference in reporting during high wind conditions. Although ERAInterim did not compare as well as ERA5 in the extreme state turbulent fluxes, it has a long record length to calculate an extreme state threshold based on a 30-yr mean, which is used in the second heat budget analysis based on the storm period. The threshold was not based on ERA5 because data prior to 2008 only recently became available. Given that ERA5 had superior relative 

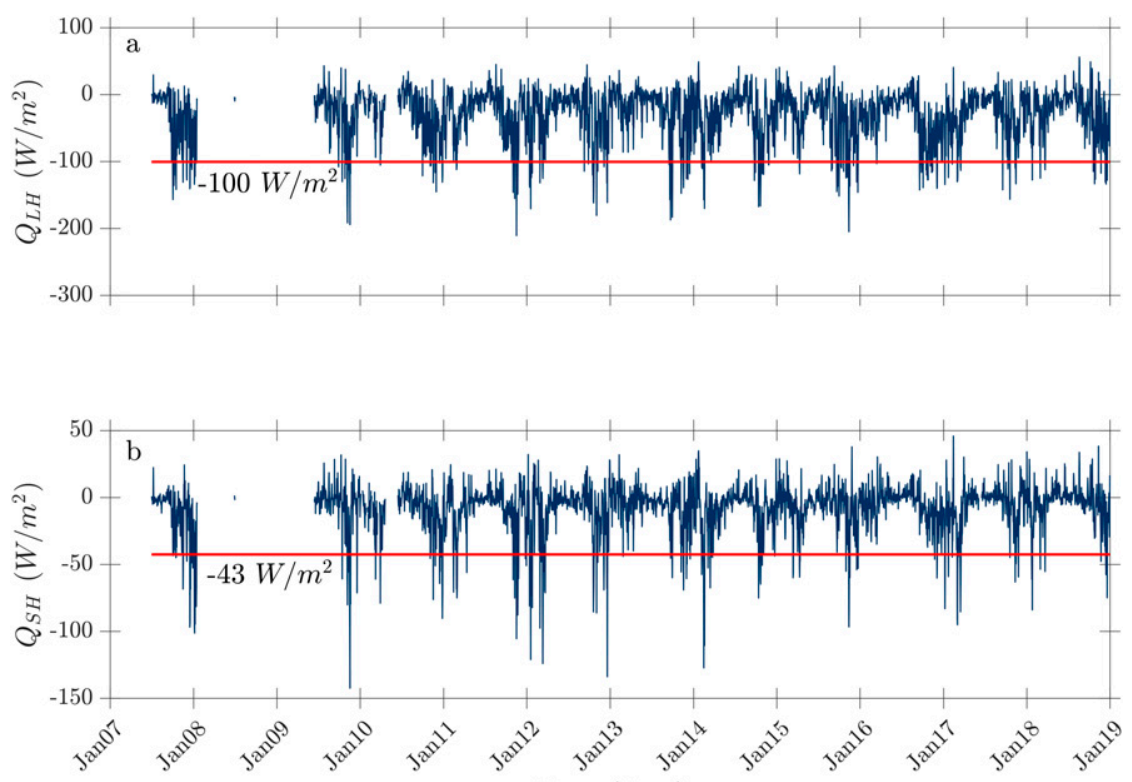

Time (days)

FIG. 7. Time series of surface turbulent heat fluxes from 2007 to 2018 from Station Papa: (a) surface latent heat flux with an extreme state threshold of $-100 \mathrm{~W} \mathrm{~m}^{-2}$ and (b) surface sensible heat flux with an extreme state threshold of $-43 \mathrm{~W} \mathrm{~m}^{-2}$. An extreme state threshold is characterized here as $-2 \sigma$ from the $11-\mathrm{yr}$ observational period mean.

skill at reproducing the heat fluxes at Station Papa, it was used as the primary dataset for surface observations and time series analysis, while a mean of all four datasets was used to calculate heat budgets during normal and extreme state conditions.

\section{c. Vertically integrated ocean subsurface heat budgets}

Generally, the Argo temperature at 100-m depth showed very little change during storm cycles (e.g., Fig. 5). Thus, the results for $h=100 \mathrm{~m}$ were less likely to be influenced by vertical redistribution of heat through the base of the layer compared with the case of $h=50 \mathrm{~m}$. Because only small amounts of subsurface warming were observed to occur in some Argo profiles between 50 and $100 \mathrm{~m}$, this analysis does not attempt to resolve entrainment or horizontal advective or mixing processes. The Argo period $\Delta t_{\mathrm{AP}}$ ranged between 11 and 23 days. This difference in time is based on the surfacing of the Argo float relative to the initial and post-storm period. Some floats surfaced in the midst of a storm cycle making it necessary to use three profiles instead of two, hence the 23-day period. The coordinate difference of roughly $0.25^{\circ}-0.30^{\circ}$ between Argo transmissions should reasonably guarantee a closed heat budget within a reanalysis grid cell.

From the approximate heat budget in Eq. (2), the Argo profiles give estimates of the time rate of change of the vertically integrated temperature on the left-hand side, while the surface heat fluxes give estimates of the surface cooling rate expected from the net surface heat fluxes alone on the right-hand side. The difference between these two estimates is due to observational errors in the temperature measurements, the uncertainties in the surface heat and radiative fluxes, the sampling error from the Argo float cycle, and oceanic heat advection and turbulent entrainment, as represented by the residual $R$. The approach taken here was to use consecutive Argo temperature profiles as end members to estimate the LHS of Eq. (2), and to use the mean $\bar{Q}_{\text {net }}$ from the reanalysis during the intervening period.

To determine the contribution of heat being transported out of the surface to the atmosphere due to an extratropical cyclone, the temperature change driven by surface heat fluxes during that exact time should be compared with the observed temperature change. However, this is not possible based on the coarse temporal sampling of the Argo float and fast moving synoptic systems. Therefore two heat budgets were calculated for this analysis: 1) one based on the observational Argo period (subscript AP) taken from an initial prestorm Argo profile to a poststorm profile to conserve energy and 2) a second based on a hypothetical temperature change during the storm period (subscript SP), which is a subset of the Argo period based on the subperiod when the surface latent heat was in an extreme state $\left(Q_{\mathrm{LH}} \leq-2 \sigma\right)$. The rationale for considering 
a) Surface latent heat flux (all time)

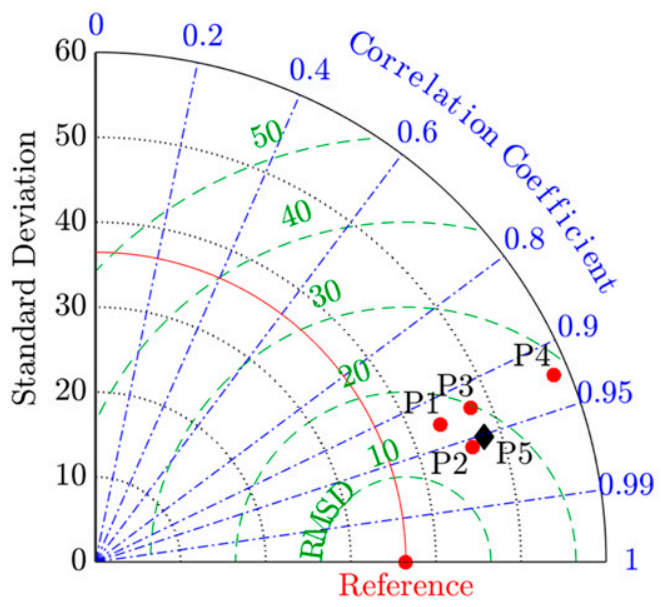

c) Surface net heat flux (all time)

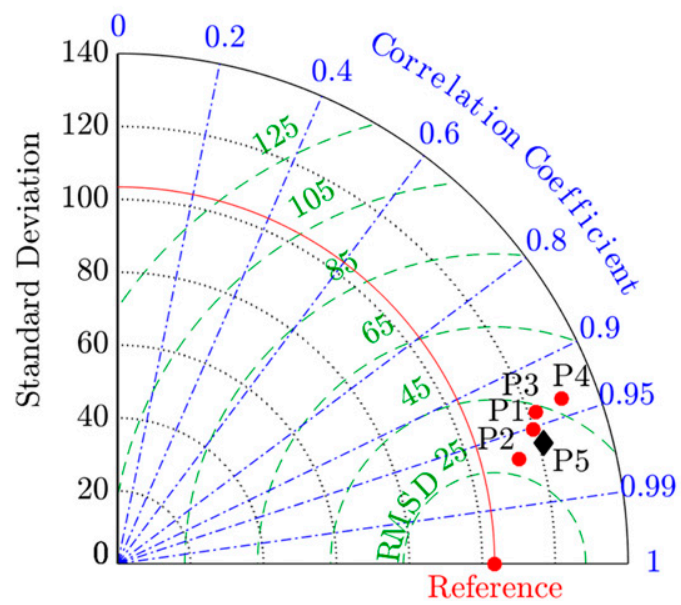

b) Surface latent heat flux (dates below threshold $\leq-100 \frac{\mathrm{W}}{\mathrm{m}^{2}}$ )

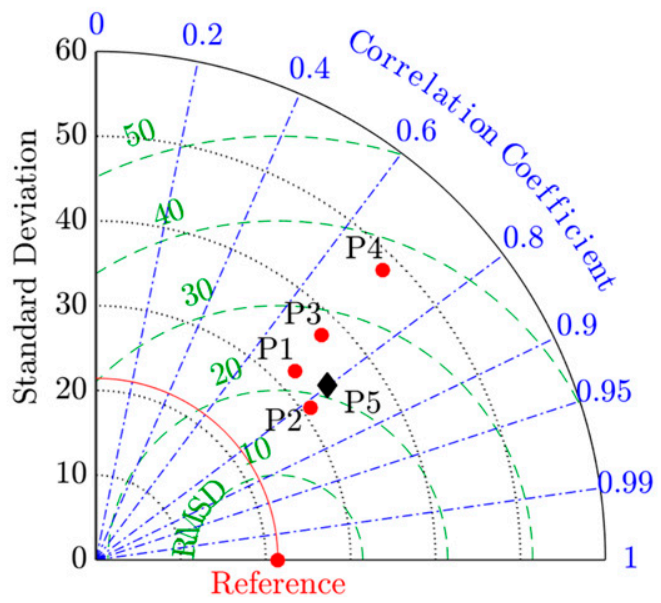

d) Surface net heat flux (dates below $Q_{L H}$ threshold)

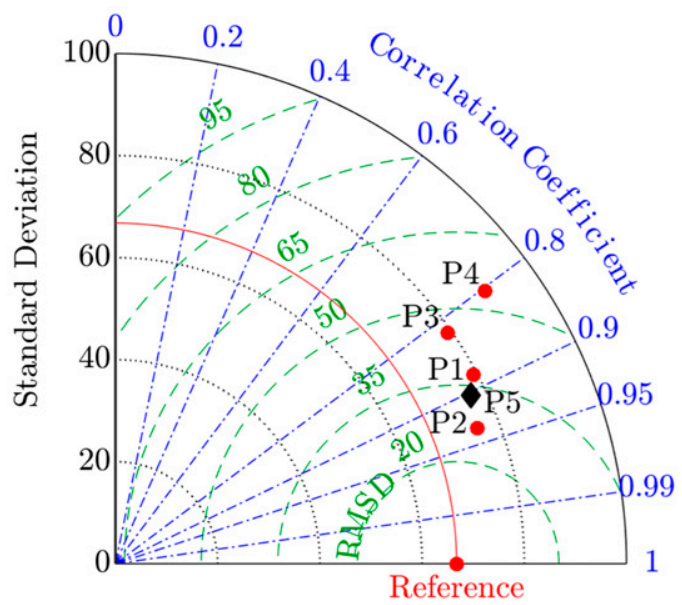

FIG. 8. Taylor diagrams of the four predictors; ERA-Interim (P1), ERA5 (P2), NCEP-1 (P3), NCEP-2 (P4), and the mean (P5) compared to the reference Station Papa from 7 Jul 2008 to 31 Dec 2018. Taylor diagrams show standard deviation $\left(\mathrm{W} \mathrm{m}^{-2}\right)$, correlation coefficient, and root-mean-square difference for (a) $Q_{\mathrm{LH}}$ and (c) $Q_{\text {net }}$ during all days in the time period and (b) $Q_{\mathrm{LH}}$ and (d) $Q_{\text {net }}$ during days when the buoy was in an extreme state. An extreme state period is any time that surpassed the surface turbulent latent heat flux threshold of $-2 \sigma$.

the storm period in isolation is that most of the surface heat loss was concentrated during just a few days when the storm and its postfrontal cold pool was directly overhead, which was several days less than the period between consecutive Argo profiles. Time series of the net surface heat flux during the storm period $\left(Q_{\mathrm{SP}}\right)$ were taken to be any time the latent heat flux was below the $-2 \sigma$ threshold. Therefore, the storm period may include any high wind conditions that surpassed the threshold during the observational period.

\section{d. Heat budgets based on observational Argo period}

The change of the vertically averaged temperature due to surface heat fluxes alone, during the Argo period, denoted here as $\Delta T_{\mathrm{AP}}$, is calculated using Eq. (2) as

$$
\Delta T_{\mathrm{AP}}=\frac{\left(\bar{Q}_{\mathrm{AP}}\right)\left(\Delta t_{\mathrm{AP}}\right)}{\rho_{0} C_{p} h},
$$

where $\Delta T_{\mathrm{AP}}$ is the change in temperature over the time interval $\Delta t_{\mathrm{AP}}$ between consecutive Argo profiles, and 
TABLE 2. Biases in the reanalysis turbulent heat fluxes (predictors 1-4) relative to Station Papa (reference) from 7 Jul 2007 through 31 Dec 2018, defined as mean(predictor) - mean(reference). Negative biases indicate that the reanalysis dataset has more ocean heat loss to the atmosphere relative to the buoy. All values are in $\mathrm{W} \mathrm{m}^{-2}$.

\begin{tabular}{lcccc}
\hline \hline $\begin{array}{c}\text { Reanalysis } \\
\text { (predictor ID) }\end{array}$ & $Q_{\text {LH }}$ & $Q_{\text {net }}$ & $\begin{array}{c}\text { Extreme } \\
Q_{\text {LH }}\end{array}$ & $\begin{array}{c}\text { Extreme } \\
Q_{\text {net }}\end{array}$ \\
\hline ERA-Interim (P1) & -15 & -12 & -24 & -35 \\
ERA5 (P2) & -19 & -20 & -37 & -47 \\
NCEP-1 (P3) & -12 & -9 & -36 & -58 \\
NCEP-2 (P4) & -21 & -4 & -73 & -75 \\
\hline
\end{tabular}

$\bar{Q}_{\mathrm{AP}}$ is the mean net surface heat flux during $\Delta t_{\mathrm{AP}}$. For this calculation, $\rho_{0}$ was a constant of $1025 \mathrm{~kg} \mathrm{~m}^{-3}$. This $\Delta T_{\mathrm{AP}}$ is then compared to the observed $(O)$ vertically integrated Argo temperature difference, denoted as $\Delta T_{O}$. Figure $3 \mathrm{e}(\mathrm{b})$ shows $\Delta T_{O}$ between the surface and $50 \mathrm{~m}$ indicated as black circles.

The Argo float highlighted in Fig. 5b was within the NEP-SSTa during the 23 September 2014 storm (E2). It was necessary to have three Argo profiles for this case to fully capture the storm; the blue line is before the storm arrived, the red line is when the storm was overhead, and the gray line is after the storm had fully passed. The time series of $Q_{\mathrm{AP}}$ is shown in Fig. 9 along with the mean $\bar{Q}_{\mathrm{AP}}$ that is used in the heat budget for this profile. The calculated temperature change for $h=50 \mathrm{~m}$ over a 22-day period was $-0.48^{\circ} \mathrm{C}$. This heat loss due to $\bar{Q}_{\mathrm{AP}}$ would have accounted for $74 \%$ of the observed change in temperature as measured by the Argo profile, $\Delta T_{O}=-0.65^{\circ} \mathrm{C}$.

\section{e. Heat budgets based on the storm period}

The storm period (SP) is defined to be any time within the Argo observational period when the surface latent heat flux exceeded a spatially varying $2 \sigma$ threshold. The threshold was calculated by subtracting $2 \sigma$ from the 30 -yr mean in the ERA-Interim surface latent heat flux time series. Each Argo float has a unique threshold based on its spatial coordinates. The change of the vertically averaged temperature profile that could be attributed to an extreme state on the surface was calculated as

$$
\Delta T_{\mathrm{SP}}=\frac{\left(\bar{Q}_{\mathrm{SP}}\right)\left(\Delta t_{\mathrm{SP}}\right)}{\rho_{0} C_{p} h},
$$

where $\bar{Q}_{\mathrm{SP}}$ is the mean net surface heat flux calculated from when the surface latent heat flux surpassed a threshold of $-2 \sigma$ from the 30 -yr mean. The value of $\Delta T_{\mathrm{SP}}$ was calculated using $\bar{Q}_{\mathrm{SP}}$ during the storm period $\Delta t_{\mathrm{SP}}$ or the duration in which the surface latent heat flux surpassed the threshold. This $\Delta T_{\mathrm{SP}}$ was then compared

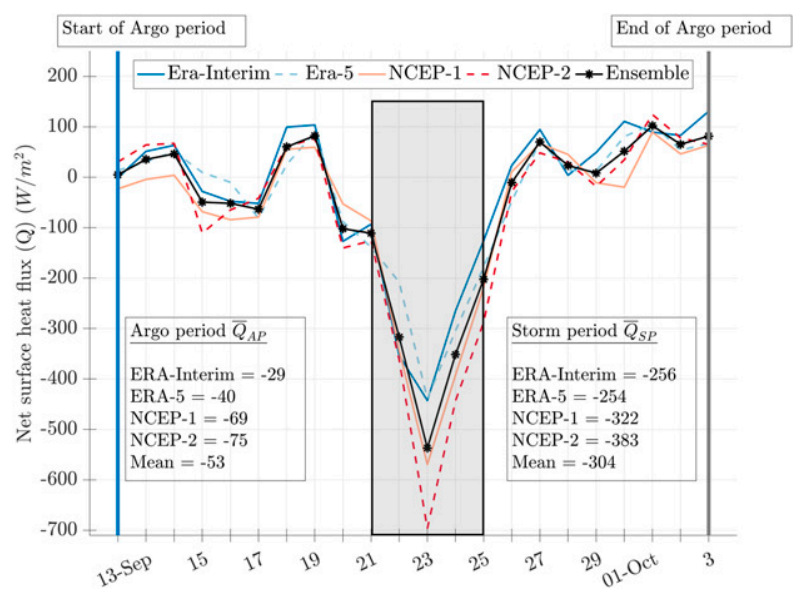

FIG. 9. Time series of the daily-averaged net surface heat flux $Q_{\text {net }}$ for Argo float 4901253 shown in Fig. 5. Reanalysis members were collocated to the floats position at $41^{\circ} \mathrm{N}, 141^{\circ} \mathrm{W}$ during the observational Argo period (AP) from 12 Sep to 3 Oct 2014. The storm period (SP), highlighted by the gray box, is defined to be any time period where the surface latent heat flux surpassed a $-2 \sigma$ threshold; this location had a threshold of $-186 \mathrm{~W} \mathrm{~m}^{-2}$. The mean $\bar{Q}_{\mathrm{AP}}$ and $\bar{Q}_{\mathrm{SP}}$ are used to calculate $\Delta T_{\mathrm{AP}}$ and $\Delta T_{\mathrm{SP}}$, respectively, in section 4 .

with $\Delta T_{O}$ to determine how much of the observed subsurface cooling could potentially be attributable to storm-induced surface heat fluxes only. For the Argo profile in Fig. 5b, the storm period is shown as the gray box within the observational period in Fig. 9. There were 5 days $\left(\Delta t_{\mathrm{SP}}\right)$ that surpassed the latent heat flux threshold; this location had a threshold of $-186 \mathrm{~W} \mathrm{~m}^{-2}$. This subset of time and the corresponding mean net surface heat flux correspond to a temperature change of $\Delta T_{\mathrm{SP}}=-0.63^{\circ} \mathrm{C}$ for $h=50$. Therefore, an extreme state at the surface has the potential to produce a temperature change that would account for $97 \%$ of the observed upper-ocean heat loss.

\section{Heat budget results}

Differences between $\Delta T_{\mathrm{SP}}$ and $\Delta T_{\mathrm{AP}}$ were not significant since most of the temperature change occurred during the storm period (Figs. 10a,b). The storm's progression over the NEP-SSTa always results in a net negative surface heat flux during the storm period $\Delta t_{\mathrm{SP}}$ which results in a corresponding negative $\Delta T_{\mathrm{SP}}$. If a profile experienced warming $\Delta T_{O}>0$ (red squares in Fig. 3, right), this would result in a negative percentage relative to $\Delta T_{\mathrm{SP}}$. Therefore, all results of $<0 \%$ (Figs. 10a,b) were neglected. This indicates that the storm had little influence on those profiles. Percentages $>200 \%$ were considered outliers and were neglected from any calculated means to reduce biased results as they grossly overestimated 


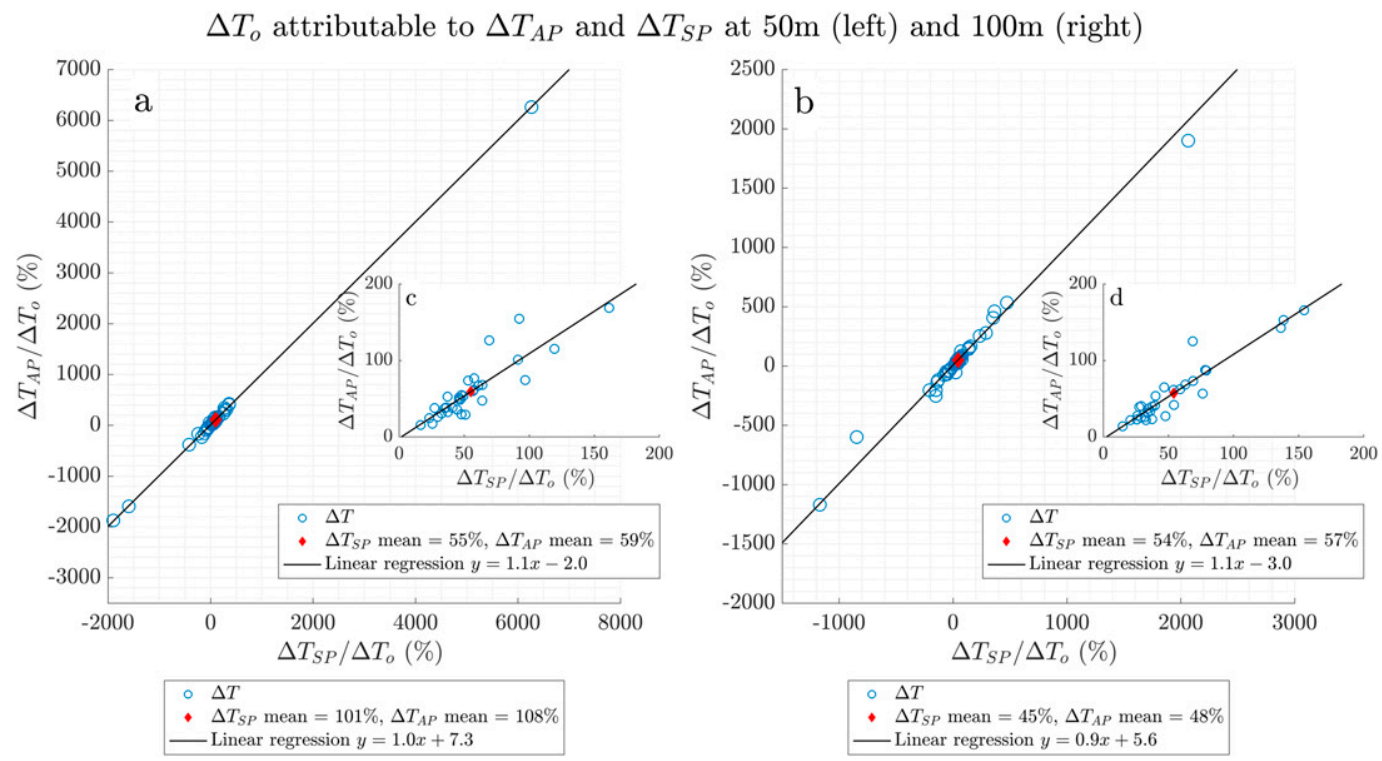

FIG. 10. Change in temperature that can be attributed to surface heat fluxes alone using $h=50 \mathrm{~m}$ and $h=100 \mathrm{~m}$ during the storm period $\Delta T_{\mathrm{SP}}$ and the Argo period $\Delta T_{\mathrm{AP}}$. Similar percentages were found in both periods since most of the temperature change occurred during the storm period. All results for (a) $h=50$ and (b) $h=100 \mathrm{~m}$ are shown in the larger plots. The inset plots for (c) $h=50 \mathrm{~m}$ and (d) $h=100 \mathrm{~m}$ magnify the larger plots to a smaller range of percentages. Mean $\Delta T_{\mathrm{SP}} / \Delta T_{O}(\%)$ and $\Delta T_{\mathrm{AP}} / \Delta T_{O}(\%)$ are shown by the red diamonds.

the degree of subsurface cooling. Out of the 39 profiles that experienced subsurface cooling (black circles in Fig. 3, right), 7 were calculated to be $>200 \%$. These temperature profiles must have warmed, corresponding to a positive $R$, within the observational period to balance the heat budget equation. This was most likely caused by vertical or horizontal advection of warmer waters into the area but was not confirmed here due to lack of data. Therefore, figures are consolidated to only include filtered results $(0 \%<$ $\Delta T_{\mathrm{SP}}<200 \%$ ) during the storm period (Figs. 10c,d) for the remainder of this section. Results for all category I events as described in section 2 during 2014-15, including two of the four fall storms described hitherto, can be seen in Fig. 11. There were 74 Argo profiles in the area during 17 of the 23 category I events. Six events failed to have enough observational data in the area to perform heat budgets. At $50 \mathrm{~m}$ $(100 \mathrm{~m})$ there were $11(15)$ events that experienced subsurface warming and 13 observations failed to surpass the $-2 \sigma$ threshold for their area.

The spatial distribution of the percentages calculated using Eq. (5) for $h=50 \mathrm{~m}$ is shown in Fig. 12. Although some percentages are shown in this figure to be situated within an area of positive surface latent heat flux, this occurred because the map is a snapshot of the ERA5 $h$ that experienced the strongest latent heat flux during the individual storm events. Figure 13 shows the results for all Argo floats in the heat budget analysis during the storm period using $h=50 \mathrm{~m}$ (red markers) and $h=$
$100 \mathrm{~m}$ (blue markers) with results during a typical extratropical cyclone duration shown as markers with stars where $\Delta t_{\mathrm{SP}} \approx 3-5$ days indicated by red bars Fig. 13a. As discussed earlier, the storm period may include any intermittent high wind events that occurred during the observational period. The distribution of the number of days $\left(\Delta t_{\mathrm{SP}}\right)$ in which the surface latent heat flux was in an extreme state during the observational period is shown in Fig. 13a. Figure 13b shows the percentage calculated by Eq. (5) as a function of $\bar{Q}_{\mathrm{SP}}$ and Fig. $13 \mathrm{c}$ shows the percentage as a function of SSTa.

Average percentages during the storm period for Argo profiles that experienced cooling over the 4-yr period down to $50 \mathrm{~m}$ was $\sim 55 \%$ (Figs. 13b,c, red diamonds) and $100 \mathrm{~m} \approx 54 \%$ (Figs. 13b,c, blue diamonds). Embedded within Figs. 13b and13c are days with a $\Delta t_{\mathrm{SP}}$ that ranged between 3 and 5 days (shown by the red bars in Fig. 13a). This was a common trend during the beginning of this analysis with a cyclone usually passing over the NEP-SSTa in 3-5 days. Average percentages during those days over the 4-yr period down to $50 \mathrm{~m}$ was $\sim 48 \%$ (Figs. 13b,c, red-starred diamond) and $100 \mathrm{~m} \approx$ $40 \%$ (Figs. 13b,c, blue-starred diamond).

Mean surface heat fluxes during the storm period $\left(\bar{Q}_{\mathrm{SP}} \approx 240 \mathrm{~W} \mathrm{~m}^{-2}\right)$ are indicated by the diamonds in Fig. 13b. Most of the Argo floats resided within an SSTa of $\geq 2{ }^{\circ} \mathrm{C}$ (Fig. 13c). The highest percentages did not always coincide with the strongest SSTa. Another 
$\Delta T_{o}$ attributable to $\Delta T_{A P}$ and $\Delta T_{S P}$ at $50 \mathrm{~m}$ (left) and $100 \mathrm{~m}$ (right) for all Category 1 Events
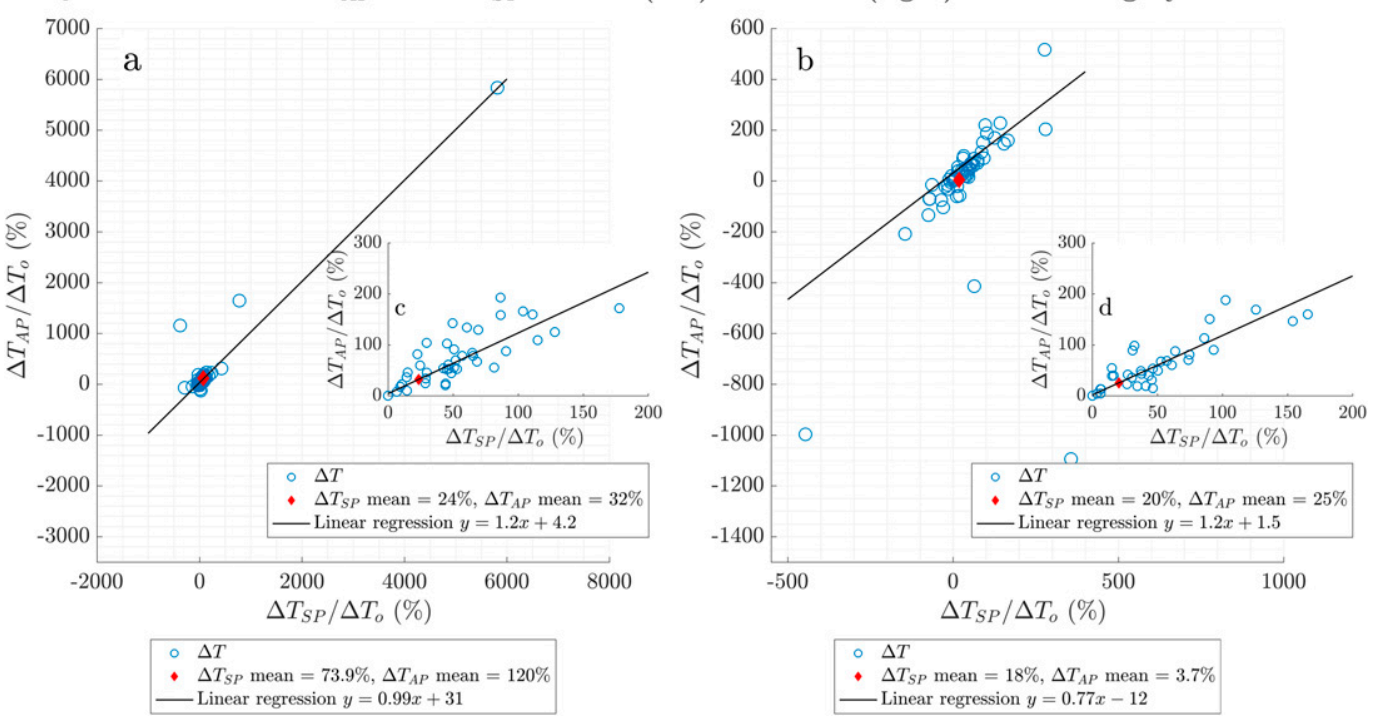

FIG. 11. Change in temperature that can be attributed to surface heat fluxes alone using $h=50 \mathrm{~m}$ and $h=100 \mathrm{~m}$ during the storm period $\Delta T_{\mathrm{AP}}$ and the Argo period $\Delta T_{\mathrm{AP}}$ for all category 1 events described in section 2 . All results for (a) $h=50$ and (b) $h=100 \mathrm{~m}$ are shown in the larger plots. The inset plots for (c) $h=50 \mathrm{~m}$ and (d) $h=100 \mathrm{~m}$ magnify the larger plots to a smaller range of percentages. Mean $\Delta T_{\mathrm{SP}} / \Delta T o(\%)$ and $\Delta T_{\mathrm{AP}} / \Delta T o(\%)$ are shown by the red diamonds.

contributing factor to the large percentages was the position of the Argo float within the cold sector of the storm. This cold sector in the southwest quadrant of the storm contains colder, drier air and when this circulates over a warm, moist SSTa, it enhances the evaporative cooling, resulting in larger percentages (Fig. 12). Differences between the years in the heat budget case studies could indicate random variability within each storm or systematic differences in the large-scale flow such as changes in the PDO or a strengthening of the Aleutian low (Alexander 1992; Di Lorenzo and Mantua 2016). This would increase surface fluxes as dry, cold air from the north dips farther south and is able to interact with the SSTa during storm events.

\section{Conclusions and discussion}

The goal of this analysis was to assess how surface heat flux anomalies associated with individual storm events in the fall during the time period between 2013 and 2016 influenced the upper-ocean warm anomaly within the GOA. Extreme surface flux anomalies associated with synoptic-scale events were shown to efficiently transfer the heat content of the upper-ocean temperature anomaly. Our results show that on average, nearly $50 \%$ of the subsurface cooling down to $50 \mathrm{~m}$ over just a 3-5day period can be explained by surface heat fluxes alone (Fig. 13b, red-starred diamond). Many Argo profiles experienced $25 \%-40 \%$ of the subsurface heat loss during storms (Fig. 13b, markers containing an asterisk), which is still a significant amount of heat being removed from the ocean instead of just being redistributed by horizontal advection or vertical mixing. This analysis did not attempt to close the heat budget, but rather to compare the contribution of subsurface cooling as calculated by surface heat fluxes relative to the observations.

Storms eroded much of the surface signature of the NEP-SSTa on synoptic time scales. This behavior differs from the timescales expected based on thermal dampening of midlatitude SST anomalies from Frankignoul and Hasselmann (1977). This difference may be at least partly due to the shallower mixed layers experienced during early fall in the northeast Pacific. Nonetheless, this analysis suggests that strong evaporative heat fluxes associated with early fall synoptic weather events also play a role in explaining the rapid dampening of the NEP-SSTa. Further work is needed to contrast the observed rapid response of the NEPSSTa with that expected from the classical thermal dampening mechanism.

Although much of the heat was pumped from the ocean via surface heat fluxes, the remainder of the subsurface heat was either pumped farther down or horizontally transported away from its original location. Figure 4 shows the $8^{\circ} \mathrm{C}$ isentrope becoming deeper over the period of $2013-16$ at $130^{\circ}$ and $140^{\circ} \mathrm{W}$; at $150^{\circ} \mathrm{W}$ 

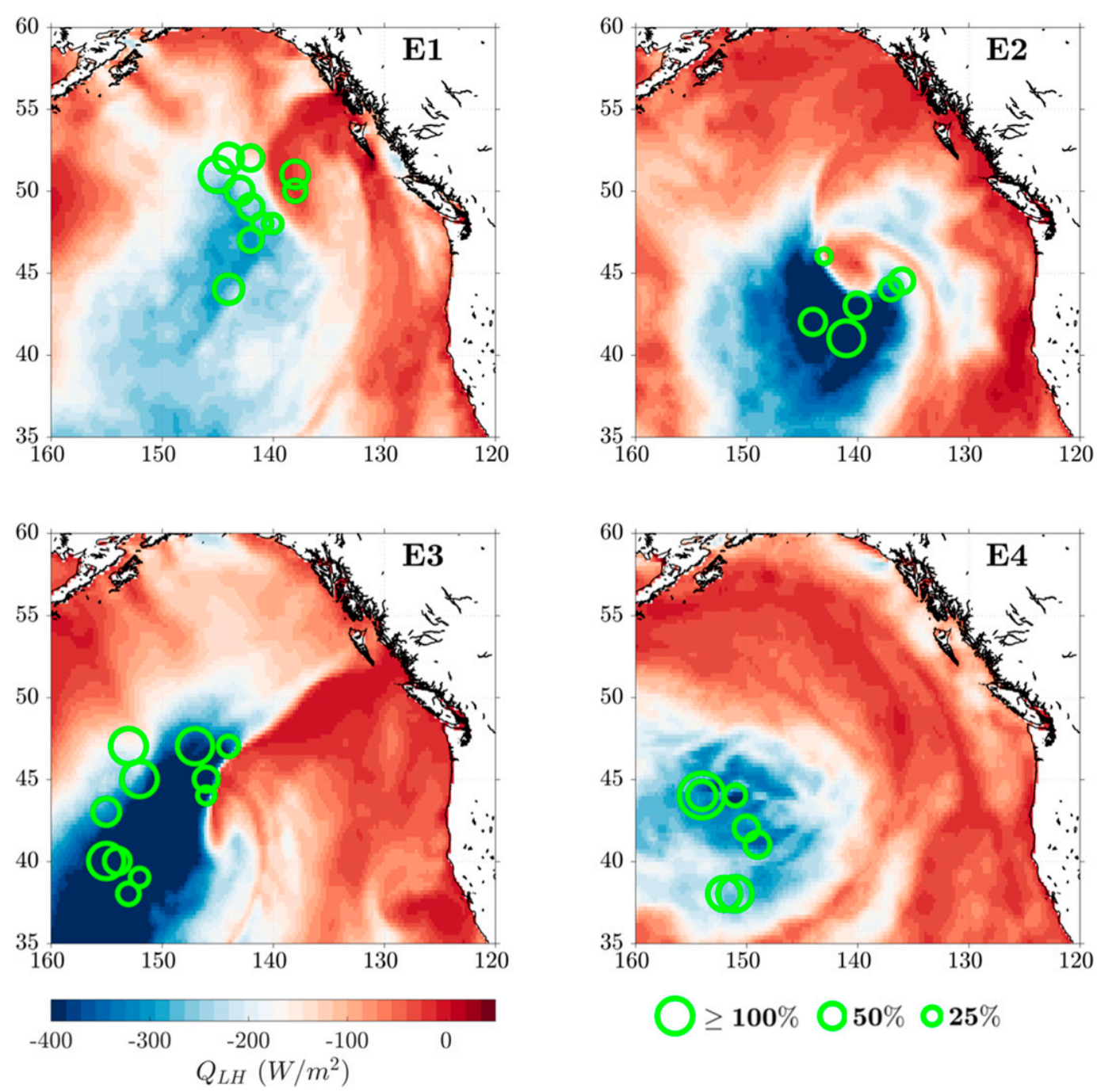

FIG. 12. Maps of ERA5 surface latent heat flux (shaded) during the storms highlighted in Fig. 2 as E1-E4. The size of the circles indicates the percentage of cooling from the surface to $50 \mathrm{~m}$ that could be explained by surface heat fluxes during the storm period (SP).

the $8^{\circ} \mathrm{C}$ isentrope deepened between 2013 and 2015 . Figure 5 shows warming did occur in the subsurface temperature as differences between the blue and gray lines are positive between $\sim 30$ and $50 \mathrm{~m}$. All negative results shown in Figs. 10a,b and 11a,b indicate warming in the subsurface. Many of the heat budget results showed a cooling at $50 \mathrm{~m}$ and a warming at $100 \mathrm{~m}$. These early fall storms may have actually assisted with increasing the NEP-SSTa residence time in the GOA by pumping heat down below the seasonal mixed layer. This could potentially be incorporated into the reemergence mechanism (Alexander et al. 1999), and could help explain the NEP-SSTa persistence in the North Pacific.
It remains an open question of how much of these warm SSTa affect the evolution of the cyclones. Extratropical cyclones that pass over positive thermal anomalies are forced to interact with increased sensible heat and moisture within a modified marine boundary layer. Increasing the temperature contrast at a fixed location has been described as a mechanism for cyclogenesis or a source for cyclone amplification (Schultz et al. 2018). With such high percentages of heat being pumped from the ocean to the atmosphere, the NEPSSTa has to be modifying the cyclone through latent heat flux. Figure 14 shows the progression of the 23 September 2014 storm's central pressure. As the cyclone moves into the area of the NEP-SSTa the central 

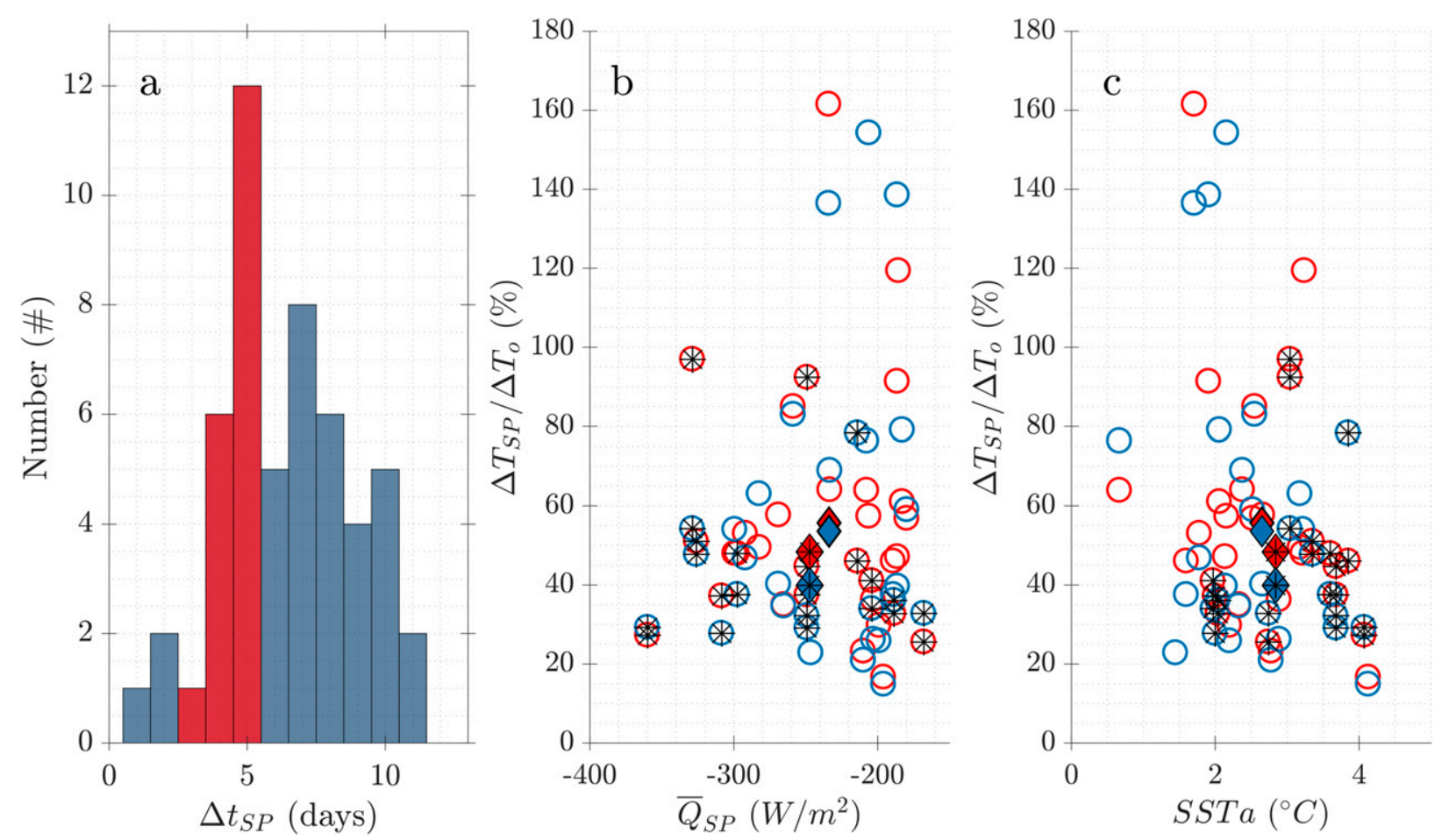

FIG. 13. Argo observation results during the storm period heat budget analysis showing (a) a histogram of the duration $\Delta t_{\mathrm{SP}}$ in which the net surface heat flux surpassed the extreme state threshold; (b) the percentage of upper-ocean cooling that is attributed to surface heat fluxes using $h=50 \mathrm{~m}$ (red markers) and $h=100 \mathrm{~m}$ (blue markers) depths as a function of the mean net surface heat flux $\bar{Q}_{\mathrm{SP}}$; and (c) the percentage of cooling as a function of Reynolds reanalysis SSTa at that location. Markers containing an asterisk are during a typical extratropical cyclone duration (3-5 days), which is indicated by the red bars in (a) as described in the text. Diamonds in (b) and (c) indicate the mean of all events and diamonds with an asterisk indicate the mean during a typical extratropical cyclone duration.

pressure decreases rapidly, reaching a minimum of $973 \mathrm{hPa}$. Future work will look at each of the fall storms described in this analysis and how they are modified during these interactions. If the NEP-SSTa becomes a permanent feature in the GOA past 2016 an interesting question may be how these SST anomalies are modifying the timing and intensity of early fall storms in the northeast Pacific. The first large fall storms are considered the first wetting rain events that assist with the extinguishing of wildfires. These fall storms picked up substantial amounts of moisture through evaporation and eventually released that moisture through precipitation along the North American coast. The late arrival of widespread precipitation could prolong wildfires along the North American west coast including Alaska but further analysis is required.

Acknowledgments. We thank Emily Shroyer and Eric Skyllingstad for valuable discussions and review of the manuscript. The authors thank the NASA Earth and Space Science Fellowship (Contract NNX16AO49H) for funding this research. L. O'Neill was supported by subcontract 1540785 from the Jet Propulsion Laboratory. We also thank two anonymous reviewers and Tim Meyers for their thorough and insightful reviews which significantly improved the manuscript.

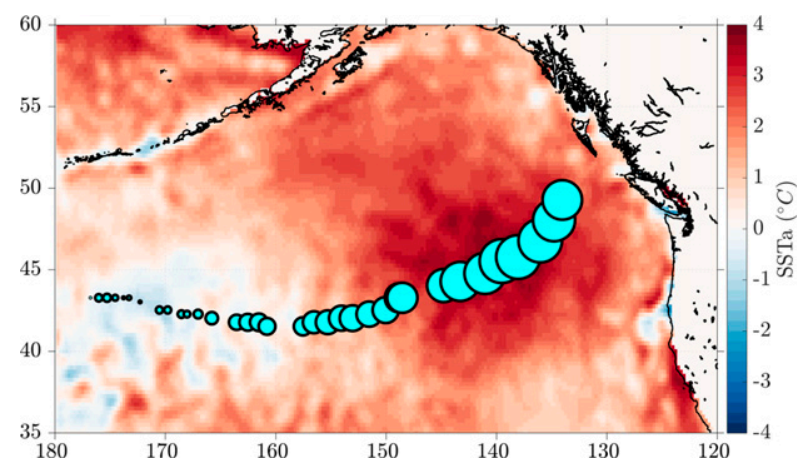

FIG. 14. Map showing the SSTa from the Reynolds SST analysis 2 days prior to the 23 Sep 2014 (E2) storm with the track of the central surface pressure (circles) from ERA5. The central pressure (circles) is inversely scaled so that the lower the pressure, the larger the circle. Minimum central pressure reached $973 \mathrm{hPa}$ at $1600 \mathrm{UTC}$ 23 Sep 2014 (largest circle near $140^{\circ} \mathrm{W}$ ). 


\section{REFERENCES}

Alexander, M. A., 1992: Midlatitude atmosphere-ocean interaction during El Niño. Part II: The Northern Hemisphere atmosphere. J. Climate, 5, 959-972, https://doi.org/10.1175/15200442(1992)005<0959:MAIDEN>2.0.CO;2.

— model driven by stochastic atmospheric forcing. J. Climate, $\mathbf{9}$, 2424-2442, https://doi.org/10.1175/1520-0442(1996)009<2424: VIAMLO $>2.0 . \mathrm{CO} ; 2$.

— C. Deser, and M. S. Timlin, 1999: The reemergence of SST anomalies in the North Pacific Ocean. J. Climate, 12, 2419-2433, https:// doi.org/10.1175/1520-0442(1999)012<2419:TROSAI>2.0.CO;2.

Amaya, D., N. E. Bond, A. J. Miller, and M. DeFlorio, 2016: The evolution and known atmospheric forcing mechanisms behind the 2013-2015 North Pacific warm anomalies. U.S. CLIVAR Variations, Vol. 14, No. 2, U.S. CLIVAR Office, Washington, DC, 1-6, https://usclivar.org/newsletter/newsletters.

Argo, 2020: Argo float data and metadata from Global Data Assembly Centre (Argo GDAC). SEANOE, accessed March 2017, https://doi.org/10.17882/42182.

Barnston, A. G., and R. E. Livezey, 1987: Classification, seasonality and persistence of low-frequency atmospheric circulation patterns. Mon. Wea. Rev., 115, 1083-1126, https://doi.org/ 10.1175/1520-0493(1987)115<1083:CSAPOL>2.0.CO;2.

Barsugli, J. J., and D. S. Battisti, 1998: The basic effects of atmosphere-ocean thermal coupling on midlatitude variability. J. Atmos. Sci., 55, 477-493, https://doi.org/10.1175/15200469(1998)055<0477:TBEOAO > 2.0.CO;2.

Bond, N. A., M. F. Cronin, H. Freeland, and N. Mantua, 2015: Causes and impacts of the 2014 warm anomaly in the NE Pacific. Geophys. Res. Lett., 42, 3414-3420, https://doi.org/ 10.1002/2015GL063306.

C3S, 2017: ERA5: Fifth generation of ECMWF atmospheric reanalyses of the global climate. Copernicus Climate Change Service, accessed May 2018, https://cds.climate.copernicus. eu/cdsapp\#!/dataset/reanalysis-era5-single-levels?tab =form.

Cronin, M. F., N. A. Pelland, S. R. Emerson, and W. R. Crawford, 2015: Estimating diffusivity from the mixed layer heat and salt balances in the North Pacific. J. Geophys. Res. Oceans, 120, 7346-7362, https://doi.org/10.1002/2015JC011010.

Dee, D. P., and Coauthors, 2011: The ERA-Interim reanalysis: Configuration and performance of the data assimilation system. Quart. J. Roy. Meteor. Soc., 137, 553-597, https://doi.org/ 10.1002/qj.828.

Deser, C., M. A. Alexander, and M. S. Timlin, 1996: Upper-ocean thermal variations in the North Pacific during 1970-1991. J. Climate, 9, 1840-1855, https://doi.org/10.1175/1520-0442(1996) $009<1840:$ UOTVIT $>2.0$. CO 2 .

Di Lorenzo, E., and N. Mantua, 2016: Multi-year persistence of the 2014/15 North Pacific marine heatwave. Nat. Climate Change, 6, 1042-1047, https://doi.org/10.1038/nclimate3082.

— , and Coauthors, 2008: North Pacific Gyre Oscillation links ocean climate and ecosystem change. Geophys. Res. Lett., 35, L08607, https://doi.org/10.1029/2007GL032838.

EUMETSAT/OSI SAF, 2010: MetOp-A ASCAT level 2 ocean surface wind vectors optimized for coastal ocean, version Operational/Near-Real-Time. PO.DAAC, accessed xxxx, https:// podaac.jpl.nasa.gov/dataset/ASCATA-L2-Coastal.

, 2013: MetOp-B ASCAT level 2 ocean surface wind vectors optimized for coastal ocean, version Operational/Near-RealTime. PO.DAAC, accessed September 2016, https://podaac. jpl.nasa.gov/dataset/ASCATB-L2-Coastal/.
Fairall, C. W., E. F. Bradley, D. P. Rogers, J. B. Edson, and G. S. Young, 1996: Bulk parameterization of air-sea fluxes for Tropical Ocean-Global Atmosphere Coupled Ocean Atmosphere Response Experiment. J.Geophys. Res., 101, 3747-3764, https:// doi.org/10.1029/95JC03205.

Frankignoul, C., 1985: Sea surface temperature anomalies, planetary waves, and air-sea feedback in the middle latitudes. Rev. Geophys., 23, 357-390, https://doi.org/10.1029/ RG023i004p00357.

_ _ and K. Hasselmann, 1977: Stochastic climate models, Part II application to sea-surface temperature anomalies and thermocline variability. Tellus, 29, 289-305, https://doi.org/ 10.3402/tellusa.v29i4.11362.

Gentemann, C. L., M. R. Fewings, and M. García-Reyes, 2017: Satellite sea surface temperatures along the West Coast of the United States during the 2014-2016 northeast Pacific marine heat wave. Geophys. Res. Lett., 44, 312-319, https://doi.org/ 10.1002/2016GL071039.

Hartmann, D. L., 2015: Pacific sea surface temperature and the winter of 2014. Geophys. Res. Lett., 42, 1894-1902, https:// doi.org/10.1002/2015GL063083.

Hoskins, B. J., and K. I. Hodges, 2002: New perspectives on the Northern Hemisphere winter storm tracks. J. Atmos. Sci., 59, 1041-1061, https://doi.org/10.1175/1520-0469(2002)059<1041: NPOTNH $>2.0 . \mathrm{CO} ; 2$.

Hu, Z.-Z., A. Kumar, B. Jha, J. Zhu, and B. Huang, 2017: Persistence and predictions of the remarkable warm anomaly in the northeastern Pacific Ocean during 2014-16. J. Climate, 30, 689-702, https://doi.org/10.1175/JCLI-D-16-0348.1.

Johnstone, J. A., and N. J. Mantua, 2014: Atmospheric controls on northeast Pacific temperature variability and change, 19002012. Proc. Natl. Acad. Sci. USA, 111, 14360-14365, https:// doi.org/10.1073/pnas.1318371111.

Kalnay, E., and Coauthors, 1996: The NCEP/NCAR 40-Year Reanalysis Project. Bull. Amer. Meteor. Soc., 77, 437-471, https://doi.org/ 10.1175/1520-0477(1996)077<0437:TNYRP>2.0.CO;2.

Kanamitsu, M., W. Ebisuzaki, J. Woollen, S.-K. Yang, J. J. Hnilo, M. Fiorino, and G. L. Potter, 2002: NCEP-DOE AMIP-II Reanalysis (R-2). Bull. Amer. Meteor. Soc., 83, 1631-1644, https://doi.org/10.1175/BAMS-83-11-1631.

Lee, M.-Y., C.-C. Hong, and H.-H. Hsu, 2015: Compounding effects of warm sea surface temperature and reduced sea ice on the extreme circulation over the extratropical North Pacific and North America during the 2013-2014 boreal winter. Geophys. Res. Lett., 42, 1612-1618, https://doi.org/10.1002/2014GL062956.

Liang, Y.-C., J.-Y. Yu, E. S. Saltzman, and F. Wang, 2017: Linking the tropical Northern Hemisphere pattern to the Pacific warm blob and Atlantic cold blob. J. Climate, 30, 9041-9057, https:// doi.org/10.1175/JCLI-D-17-0149.1.

Mantua, N. J., S. R. Hare, Y. Zhang, J. M. Wallace, and R. C. Francis, 1997: A Pacific interdecadal climate oscillation with impacts on salmon production. Bull. Amer. Meteor. Soc., 78 , 1069-1079, https://doi.org/10.1175/1520-0477(1997)078<1069: APICOW $>2.0 . \mathrm{CO} ; 2$.

Myers, T. A., C. R. Mechoso, G. V. Cesana, M. J. DeFlorio, and D. E. Waliser, 2018: Cloud feedback key to marine heatwave off Baja California. Geophys. Res. Lett., 45, 4345-4352, https:// doi.org/10.1029/2018GL078242.

NCEP, 2006: NCEP Global Ocean Data Assimilation System (GODAS). Research Data Archive at the National Center for Atmospheric Research, Computational and Information Systems Laboratory, accessed March 2018, https://doi.org/ 10.5065/ZAHZ-3174. 
Reynolds, R. W., T. M. Smith, C. Liu, D. B. Chelton, K. S. Casey, and M. G. Schlax, 2007: Daily high-resolution-blended analyses for sea surface temperature. J. Climate, 20, 5473-5496, https://doi.org/10.1175/2007JCLI1824.1.

Scannell, H. A., A. J. Pershing, M. A. Alexander, A. C. Thomas, and K. E. Mills, 2016: Frequency of marine heatwaves in the North Atlantic and North Pacific since 1950. Geophys. Res. Lett., 43, 2069-2076, https://doi.org/ 10.1002/2015GL067308.

Schultz, D. M., and Coauthors, 2018: Extratropical cyclones: A century of research on meteorology's centerpiece. A Century of Progress in Atmospheric and Related Sciences: Celebrating the American Meteorological Society Centennial, Meteor. Monogr., No. 59, Amer. Meteor. Soc., https://doi.org/10.1175/ AMSMONOGRAPHS-D-18-0015.1.

Swain, D. L., M. Tsiang, M. Haugen, D. Singh, A. Charland, B. Rajaratnam, and N. S. Diffenbaugh, 2014: The extraordinary California drought of 2013-2014: Character, context, and the role of climate change [in "Explaining Extremes of 2013 from a Climate Perspective"]. Bull. Amer. Meteor. Soc., 95 (9), S3-S7.

D. Singh, D. E. Horton, J. S. Mankin, T. C. Ballard, and N. S. Diffenbaugh, 2017: Remote linkages to anomalous winter atmospheric ridging over the northeastern Pacific. J. Geophys. Res. Atmos., 122, 12 194-12 209, https://doi.org/10.1002/2017JD026575.

Taylor, K. E., 2001: Summarizing multiple aspects of model performance in a single diagram. J. Geophys. Res., 106, 71837192, https://doi.org/10.1029/2000JD900719.

Wang, S.-Y., L. Hipps, R. R. Gillies, and J.-H. Yoon, 2014: Probable causes of the abnormal ridge accompanying the 2013-2014 California drought: ENSO precursor and anthropogenic warming footprint. Geophys. Res. Lett., 41, 32203226, https://doi.org/10.1002/2014GL059748.

Wills, S. M., and D. W. J. Thompson, 2018: On the observed relationships between wintertime variability in Kuroshio-Oyashio Extension sea surface temperatures and the atmospheric circulation over the North Pacific. J. Climate, 31, 4669-4681, https://doi.org/10.1175/JCLI-D-17-0343.1. 